\title{
ACCELERATED LABORATORY CORROSION TEST METHODS FOR ZINC-COATED STEEL
}

\author{
By Edward C. Groesbeck and William A. Tucker
}

\begin{abstract}
The merits of two certain types of accelerated laboratory testing methods for evaluating the indicated life of the coating on hot-dip zinc-coated sheet steel were compared. The two methods studied were the simulated atmospheric corrosion, using a moist gaseous mixture of sulphur dioxide, carbon dioxide, and air, and the spray, using normal solutions of sodium chloride and ammonium chloride separately. A consistent relationship between the "life" and weight of the coating was shown by the results. The time required for the breaking down of the coating was considerably less for the first method than for the second. The coating was corroded, in the first method, in a progressive manner over the entire surface and similar to that reported for galvanized materials corroded in the atmosphere under service conditions, and in the second method, in a local and capricious manner. No attempt was made to interpret the experimental results in terms of service life in various types of atmospheres prevailing in different climates. Any satisfactory attempt at such an evaluation will have to await the results of long-time field tests on zinc-coated products carried out under several typical atmospherical conditions obtaining at different locations. The presence or absence of about two-tenths of 1 per cent copper in the steel base produced no apparent effect on the results. Tests were also made on specimens which had been annealed for the purpose of converting the zinc coating into an iron-zinc alloy.
\end{abstract}

\section{CONTENTS}

I. Introduction

II. Previous work

1. Simulated atmospheric corrosion method

2. Spray test method... 263

III. Materials and experimental methods 264

1. Materials_........ 264

2. Experimental methods

(a) Simulated atmospheric corrosion test_...... 268

(b) Spray tests

IV. Experimental results.

V. Discussion of results _._.

1. Simulated atmospheric corrosion test

2. Spray tests

(a) Sodium chloride._._. 287

(b) Ammonium chloride... 290

VI. Summary and conclusions. 292 


\section{INTRODUCTION}

A reliable means of forecasting the probable life under severe atmospheric conditions of "galvanized" materials is much to be desired, since these materials (amounting to about 1,350,000 tons in 1926) constitute a very considerable proportion of the annual production in the United States of iron and steel products to which a metallic protective coating of one kind or another has been applied for the purpose of prolonging their useful life by postponing as long as possible the inevitable corroding away of the underlying iron or steel. (The term "galvanized" used throughout this paper refers to material zinc coated by any process, other than that in which electrodeposition is employed for the coating operation. Immersion in a bath of molten zinc - that is, the hot-dip process-is the most common.) Of course, field tests carried out on specimens of galvanized materials exposed to conditions as similar to those obtaining in actual service as practicable should furnish the desired information, but much time (probably several years) must elapse between the start of the test and the appearance of the first definite signs of failure of the protective coating. This is particularly true when the field test is carried out in a locality where the prevailing atmospheric conditions are not of a markedly corrosive nature, and also when specimens with relatively heavy zinc coatings are included in the test. A laboratory test method so devised that it would furnish results which will serve as a reliable index of the behavior obtaining under actual service conditions and, indeed, yield information similar to that produced by the field tests, but in a very much shorter time, should be of much value to the industry. In such an accelerated test, one or more of the important controlling factors present in service conditions must be exaggerated in order that the corroding effect may be made to proceed at a more rapid rate.

It is apparently only within the last few years that any definite efforts have been made to develop such an "accelerated test" of metallic coatings for the sole purpose of ascertaining the probable life of the coating. The so-called "stripping tests" are not to be included in this category, since the main objects of these tests are to give the total amount of the zinc coating present on a surface and to reveal the presence of thin spots in the coating. Another type of laboratory testing which should not be classed with these "life tests" is that designed to bring out any defects present in the coating, such as pinholes and other forms of discontinuity in the covering qualities of the coating, particularly of the electroplated kind.

The following report gives the results of experiments undertaken to test, on a comparative basis, two certain types of laboratory testing methods for determining the "life" of the coating on "hot-dip" 
galvanized sheets with the object of determining their value as an "accelerated test." One type is known as the "simulated atmospheric corrosion test," wherein the specimens are exposed to a muggy, acidic atmosphere corresponding in nature, although much more concentrated in acid content, to that of ten prevailing in certain industrial districts, as, for example, Pittsburgh, Pa. The results of such a test would, of course, not be comparable to those obtaining in another and less corrosive type of atmosphere but could be taken as a measure of the life of the coatings under the severest service conditions galvanized products would ordinarily be subjected to. The measures for the other types of atmospheric conditions might be expected to bear ratios to this measure as obtained above. These ratios would have to be determined by experiment or by the results of long-time field tests carried out under a set of different typical atmospheric conditions. The other type of testing method tried is based on the well-known salt spray test. The essential value of this method would seem to lie in the use of a corroding solution, which, when atomized within the chamber containing the test specimens, would be expected to remove the zinc coating in a progressive and more or less even manner within a reasonable period of time. The two corroding solutions tried out in this investigation were normal solutions of sodium chloride and ammonium chloride.

Two classes of hot-dip galvanized sheet material were used for the experimental work, namely, copper-bearing and noncopper-bearing sheet steel or iron, for the purpose of determining whether or not the presence of copper, totaling about two-tenths of 1 per cent, in the steel base, in addition to the small amount usually present in noncopper-bearing steel, would exert any clearly defined influence on the resistance to accelerated attack of the zinc coating. The galvanized sheet material was mostly of 22 and 28 gauge, and the weights of zinc coating ranged from about 0.75 to 2.5 ounces of zinc per square foot of sheet. A few test specimens, which had been heat treated after the galvanizing process with the object of obtaining a larger proportion of, and a more evenly distributed, iron-zinc alloy in the coatings, were also included in the tests.

All references to weight of zinc coating expressed throughout this paper are in the terms of the weight, in ounces, of the coating per square foot of sheet (that is, the coating on both faces of the sheet), unless otherwise stated. 


\section{PREVIOUS WORK}

\section{SIMULATED ATMOSPHERIC CORROSION METHOD}

The fact that the zinc coating of a galvanized article is very slowly attacked during exposure to a normal, relatively uncontaminated atmosphere is a matter of common knowledge. The surface of the coating reacts with the oxygen and carbon dioxide of the atmosphere in the presence of moisture. This reaction leads to the formation of a very thin adherent film of basic zinc carbonate or a mixture of zinc carbonate and zinc oxide which is apparently quite resistant to ordinary weathering effects. This protective film is subjected to the eroding effects of wind and rain and may possibly be affected by temperature changes in so far as the differential expansion of the metal coating and the overlying adherent film leads to the cracking of the latter. The eroding effect of the wind and rain will, of course, depend largely upon the amount and nature of the dust suspended in the atmosphere. Furthermore, the dust in the atmosphere of seacoastal, desert, and industrial regions contains appreciable proportions of sodium chloride, alkalies, and sulphur compounds present in the cinder or ash particles, respectively, and, therefore, should exert, in the presence of moisture, a corroding influence, As the film deteriorates and wears away, it is replaced by a new one. This building up and breaking down of the protective film constitutes a continuous process, which may be an extremely slow one in a region where a quite pure and dry atmosphere prevails, until the zinc coating is entirely consumed at some points.

In certain regions, such as large cities and industrial centers, there are present in the atmosphere appreciable amounts of carbonic acid, sulphur dioxide, and sulphurous acid (and even sulphuric acid in much smaller quantities), more noticeably so where foggy or misty weather prevails and also during the winter months when the coal consumption is necessarily greater. Because of their relatively high solubility, the zinc sulphates and sulphites forming in the protective film by the reaction with the acid-laden atmosphere would tend to break the film up and lay bare the underlying zinc coating to the corrosive influences of the atmosphere. It is within the bounds of reason to expect that the corroding away of the zinc coating would thus be accelerated.

The presence of a continuous zinc coating is, of course, assumed in the above discussion of the corroding effects, and, hence, any consideration of electrochemical reactions between the coating and base metal has no place in this stage of corrosive attack.

- Galvanized materials are known to have a much shorter life in a highly corrosive atmosphere, such as that prevailing in the Pittsburgh, $\mathrm{Pa}$., district, than those in the relatively very pure atmosphere 
of a country district, which may be even only 100 miles distant. Even though no numerical data as to the comparative life of zinc coatings in various atmospheres appear to have been published, the following estimate by Hubbell and Finkeldey ${ }^{1}$ may be mentioned as a matter of interest:

TABLE 1.-Estimated life of galvanized products in several types of atmosphere

\begin{tabular}{|c|c|c|c|c|}
\hline \multirow{2}{*}{ Class of material } & \multicolumn{4}{|c|}{ Type of atmosphere } \\
\hline & Rural & Seacoast & $\begin{array}{c}\text { Semi- } \\
\text { industrial }\end{array}$ & $\begin{array}{c}\text { Heavy } \\
\text { industrial }\end{array}$ \\
\hline $\begin{array}{l}\text { Commercial rolled zine sheet or strip } 0.020 \text { inch thick } \\
\text { Galvanized product } 1.25 \mathrm{ounce} \text { coating/sq. } \mathrm{ft} \text {. of surface } \\
\text { Galvanized product } 1.0 \mathrm{oz} . / \mathrm{sq} \text {. } \mathrm{ft} \text {. of surface } \\
\text { Galvanized product } 0.6 \mathrm{oz} \text {./sq. } \mathrm{ft} \text { of surface } \\
\text { Galvanized product } 0.2 \text { to } 0.3 \mathrm{oz} . / \mathrm{sq} \text {. ft. of surface }\end{array}$ & $\begin{array}{r}\text { Years } \\
50-75 \\
30-35 \\
20-25 \\
8-10 \\
3-4\end{array}$ & $\begin{array}{r}\text { Years } \\
50 \\
20-25 \\
15 \\
5-8 \\
2-3\end{array}$ & $\begin{array}{r}\text { Years } \\
20-30 \\
15-20 \\
10-15 \\
5 \\
1-2\end{array}$ & $\begin{array}{r}\text { Years } \\
10-15 \\
8-10 \\
6-8 \\
3-5 \\
1\end{array}$ \\
\hline
\end{tabular}

The types of failure produced in galvanized materials by exposure to severely corroding atmospheres have been observed to be quite similar in appearance to those obtained by long exposures to less corrosive atmospheres.

It is only natural that there should have arisen, in connection with the search for laboratory methods of determining the comparative life of galvanized products, the idea of developing a simulated atmospheric corrosion test method, in which the proportions of the corrosive elements present in the atmosphere are accentuated with the sole object of shortening in a large degree the time required for the zine coating to be corroded away. Szirmay published in $1905^{2}$ an account of some tests made to determine the relative resistance of iron and steel wires, zinc coated by the electroplating and "hot-dip" galvanizing processes, by exposing them to a gaseous mixture of air, $\mathrm{CO}_{2}$, and $\mathrm{SO}_{2}$ over moderately heated water. The wire specimens were kept in a bell jar, which was placed in a basin partly filled with water, and the two gases were passed into the bell jar in the proportions of 12 per cent $\mathrm{SO}_{2}$ and 15 per cent $\mathrm{CO}_{2}$ in the resulting mixture. Heyn and Bauer ${ }^{3}$ later employed a similar method in carrying out some tests on the relative resistance to corrosion of the zinc coating on electroplated and hot-galvanized pipes. A few years ago the New Jersey Zinc Co. developed a "plant-size" testing apparatus designed for testing comparatively large sized specimens of galvanized sheets and other products. ${ }^{4}$ This apparatus was essentially a

\footnotetext{
${ }^{1}$ Hubbell, J. P., and Finkeldey, W. H., Trans. Amer. Inst. Chem. Engrs., 18, p. 51; 1926.

${ }^{2}$ Szirmay, I., "Testing the corrodibility of zinc-coated iron and steel wire, including barbed wire," Zeit. Elektrochem., 11, p. 333; 1905.

${ }^{3}$ Heyn, E., and Bauer, O., "Corrosion tests of galvanized tubes," Mitt. Kgl. Materialprüfungsamt, 30, p. 101; 1912.

"Rawdon, H. S., Krynitsky, A. I., and Finkeldey, W. H., "Types of apparatus used in testing the corrodibility of metals," Proc. Amer. Soc. Test. Matls., 24, pt. 2, p. 731; 1924.
} 
rectangular-shaped, lead-lined wooden tank with a lead-lined cover fitting into a troughlike arrangement on the sides, which when filled with water served as a water seal during operation. The tank was filled to a certain height with water, which was heated by electric heaters placed at the bottom. A mixture of 100 parts air, 5 parts $\mathrm{CO}_{2}$, and 1 part $\mathrm{SO}_{2}$, the proportions being controlled by flow meters, was passed into the tank at one end and just above the water level, along over the water surface and under a false bottom to the opposite end, and thence upward into the specimen chamber above the false bottom. The proportions used in this air-gas mixture were arbitrarily chosen, as they were found in some preliminary tests to produce a failure of the zinc coating within a reasonable length of time (a slight modification of these proportions was adopted subsequently, namely, 94 parts air instead of 100). The air-gas mixture was admitted at the rate of approximately 6.4 liters per minute, and it became warmed and then saturated with water vapor as it passed through the lower part of the tank. The temperature of the water was thermostatically regulated so as to give a temperature of $55^{\circ} \mathrm{C}$. $\left(131^{\circ}\right.$ F.) in the atmosphere within the specimen chamber. An exhaust pipe, large enough to prevent the building up of pressure in the air-gas mixture within the tank during operation, was provided in the upper part of the tank. The test was carried out in three steps: (1) Exposure to the warm, moist gaseous mixture for 10 hours; (2) thorough washing of the specimens with water, furnished by a sprinkling system which was placed below the top edges of the tank, for 2 hours (this was intended to imitate the washing action of rain, which would remove more or less completely the corrosion products from the surface); and (3) drying of the specimens by exposure to the ordinary surrounding atmosphere (with the tank cover removed) at room temperature for 12 hours-here the zinc coating should have the opportunity to renew its protective film which had been removed or damaged during the preceding exposure to the corroding conditions. These three steps constituted a cycle, and the number of cycles required to produce a definite rusting of the base metal was taken as a measure of the life of the protective coating, or, in other words, an indirect measure of the ability of the coating to withstand atmospheric corrosion.

It must be admitted that this form of test by no means constitutes an atmospheric corrosion test in the true sense of the word, but it does produce types of failure in the zinc coating which are similar to those occurring under actual conditions of atmospheric corrosion (at least, so far as can be judged by surface appearance), and with the added advantage of requiring very much less time to attain these results. According to Finkeldey, ${ }^{5}$ the progressive changes in the

${ }^{3}$ See discussion on p. 757 of reference cited in footnote 4, p. 259. 
appearance of galvanized sheet specimens carrying light and heavy coatings of zinc, as revealed in test by the New Jersey Zinc Co.'s simulated atmospheric corrosion test method, is about as follows: After the first or second cycle the coating loses its metallic luster and becomes covered with a light gray-colored protective film; after additional cycles the spangles gradually disappear, and then darkcolored spots begin to appear on the surface of the specimen. After a few more cycles the entire surface of the specimen assumes a dark color. This change in color from light to dark gray is ascribed to the removal of the zinc layer and the consequent laying bare of the iron-zine alloy layer overlying the iron base. Exposure to several additional cycles will remove this alloy layer, and the iron base thus laid bare will start rusting. There is a very close resemblance between the appearance of the coating on specimens during the progress of the accelerated test and that of the coating on ordinary galvanized iron as it fails in the atmosphere; the revealing of the dark-colored alloy layer is the principal characteristic feature of this similarity. It has been repeatedly observed that, with heavily coated galvanized iron, a larger number of cycles is required to bring out the first spots of the dark-colored alloy layer than in the case of the lightly coated material. When exposed to the atmosphere these two classes of galvanized iron have been observed to show the same characteristic difference of performance. To put it in another way, the length of time required for the dark spots to show up on the galvanized material when exposed to atmospheric conditions should constitute a good index of the relative thickness, at the thinnest point, of the zinc coating overlying the iron-zinc alloy layer. However, no information has been forthcoming as to the relative rates of corrosion in the atmosphere of the zinc and zinc-iron alloy layers; it is to be expected that these rates would probably vary with the composition and thickness of the two layers.

The only experimental data obtained by this simulated atmospheric corrosion method that has been published to date are those reported by the New Jersey Zinc Co.'s research laboratory ${ }^{6}$ for a number of special steel specimens, coated with zinc by several processes and with lead by the metal spray process, in connection with a series of short-time tests undertaken by several laboratories in co_ operation with Subcommittee VII of Committee A-5, American Society for Testing Materials.

At a little later date, and apparently independently, Fowle ${ }^{\text {? }}$ developed a simulated atmospheric corrosion test method and apparatus somewhat similar, in general details, to that worked out by the

\footnotetext{
- Report of Subcommittee VII on Accelerated tests. Proc. Amer. Soc. Test. Matls., 26, Pt. I, p. 147; 1926.

7 Fowle, F. F., "Accelerated corrosion tests on bare overhead electrical conductors," Proc. Amer. Soc. Test. Matls., 25, Pt. II, p. 137; 1925.
} 
New Jersey Zinc Co., but primarily for testing uninsulated overhead electrical conductors. The essential difference was that instead of the $\mathrm{SO}_{2}$ gas- $\mathrm{CO}_{2}$ gas-air mixture dilute bituminous coal smoke, which was generated outside of the test box, was employed to produce in a more moderate degree the simulation of the corroding influence of outside atmospheres prevailing in city and industrial regions.

The chemical action of the smoke in both gaseous and finely divided solid form upon the protective coating should, in the presence of moisture, be of an acidic nature and, therefore, be similar, though different in degree, to that of the gaseous mixture employed in the other method. The materials under test-namely, copper, aluminum, iron, steel, copper-clad steel, and galvanized iron and steel in wire and strand form-were exposed repeatedly to the simulated weathering effects in cycles of short duration. Each cycle lasted 8 hours and was divided into four periods-(1) warm moist air, 1.5 hours; (2) air charged with bituminous coal smoke, 3 hours; (3) fine water spray, 0.5 hour; and (4) warm dry air, 3 hours. The first period was intended to simulate a normal atmospheric condition which prevails during much of the time, the second and third periods introduced the chief corroding agents (the water spray to simulate the action of rain), and the fourth period to secure thorough drying of the specimens and the box following the water-spraying operation. The repetition of cycles was maintained continuously day and night, excepting Sundays, holidays, and occasional interruptions. A gentle circulation of air and smoke, maintained by an exhaust fan placed at one end of the test box, was directed up and down along the length of the box by means of transversely placed baffle plates. The coalsmoke atmosphere was found by analysis, made on two different occasions, to contain from 5.1 to 8.6 per cent $\mathrm{CO}_{2}$ and, as determined at the center of the box, 86 parts, by volume, of sulphuric acid per million parts, by volume, of total gas. The temperature in the box obtaining under the different conditions of the test ranged from 14 to $42^{\circ} \mathrm{C}$. (57 to $108^{\circ} \mathrm{F}$.). The specimens, which were initially about 14 feet long and placed along the length of the test box, were taken out and examined at intervals. The specimens of galvanized iron and steel were reported as having shown a progressive change of appearance similar to that described by Finkeldey, as noted above.

A laboratory test apparatus, designed on similar general principles as that of the New Jersey Zinc Co., but differing mainly in constructional details, was developed at this bureau. ${ }^{8}$ A description of this apparatus, which was subsequently modified in several constructional details, and the results of a program of tests carried out with this apparatus on several types of "hot-dip" galvanized sheet-steel material are given in the following sections.

8 See footnote 4, p. 259. 
Speaking in a larger sense, we must accept the truth that the varying nature of climatic conditions, both regional and seasonal, should render the formulation of a simulated atmospheric corrosion testing method which would be universally adaptable to all types of atmospheric corrosion an extremely difficult, if not impossible, matter. However, it seems possible that, if we should take the measure given by the simulated atmospheric corrosion test as being representative of the severest corroding set of conditions likely to be found in the atmosphere, we could apply, for any definite kind and weight of zinc coating, a ratio of this measure to each of the various types of atmospheric conditions of a less corrosive nature. Such ratios could probably be best determined, on a practical basis, by the results of field tests carried out at various localities where different and distinct types of atmospheric conditions prevail. Considerable lengths of time would necessarily elapse before the results of such field tests could be made available, particularly those tests carried out in localities where the corroding conditions are not severe.

The American Society for Testing Materials, through Subcommittee VIII of its Committee $\mathrm{A}-5$, has had in progress during the past two years at five localities an extensive program of field tests undertaken on a series of galvanized and other metallic-coated products. ${ }^{9}$ These localities were selected as being representative of the following five types of atmospheric conditions: Severe industrial, moderate industrial, rural, foggy seacoast, and tropical seacoast. The results of these field tests, when they are completed, should be of great value in determining the ratios between the different types of atmospheric exposure. The principle of applying ratios, for each kind and weight of zinc coating, would, of course, be only an approximation but should, however, serve as a reliable index of the probable service behavior of the material that could be obtained on a laboratory basis and within a reasonable period of time.

\section{SPRAY-TEST METHOD}

The first application of the spray method type to the testing of metallic protective coatings appears to have been made some 20 years ago. ${ }^{10}$ This method of testing has been described in detail in several subsequent publications ${ }^{11}$ in connection with its use for testing different metals in various corrodents.

The essential feature of this test consists in exposing the test specimens to the corrodent in the torm of a very fine spray or mist

\footnotetext{
- Report of Subcommittee VIII on Field tests of metallic coatings, Proc. Amer. Soc. Test. Matls., 27, Pt. I, p. 191; 1927.

${ }^{10}$ Capp, J. A., "A rational test for metallic coatings,” Proc. Am. Soc. Test. Matls., 14, Pt. II, p. 474; 1914.

11 (a) Finn, A. N., "Method of making the salt-spray test," Proc. Amer. Soc. Test. Matls., 18, Pt. I, p. 237; 1918. (b) B. S. Circular No. 80, 2d ed.; 1922. (c) See footnote 4, p. 259. (d) Rawdon, H. S., and Groesbeck, E. C., B. S. Tech. Paper No. 367, The Effect of the Testing Method on the Determination of Corrosion-Resistance; 1928. (e) Whitman, W. G., and Chappell, E. L., "Corrosion of steels in the atmosphere," Ind. Eng. Chem., 18, p. 533; 1926. This form of apparatus is different from that described in the above references and was developed for testing bare-steel specimens by exposing them to intermittent spraying with water, in connection with life tests carried out on the same steel materials in the atmosphere at different localities.
}

$109748^{\circ}-28-2$ 
and noting the length of time required for the metallic coating on the specimen to break down. The specimens are placed in a suitable box, and the mist is produced within the covered box by atomizing the solution with compressed air under moderate pressure, care being taken to prevent, by means of baffle plates, the direct impinging of the sprayed stream on the specimens. In general, the mist would be expected to condense and collect over the surface of the specimen as a very thin liquid film, but actually a coalescing of the liquid into easily visible aggregates occurs at more or less favorable locations on the surface during the course of the exposure.

\section{MATERIALS AND EXPERIMENTAL METHODS}

\section{MATERIALS}

Since a comparative study of the two types of laboratory corrosion testing methods, as used for determining the "life" of the zinc coating on galvanized iron or steel products, was the main object of this investigation, the materials used in this study were confined to iron and steel sheets of different gauges and with various weights of zinc coating applied by the hot-dip galvanizing process. These materials, which were made under commercial conditions, are listed in Table 2.

There were included in these materials two series of galvanized sheets, having the same gauges and weights of zinc coating, which had for the base metal ordinary noncopper-bearing open-hearth steel in one and copper-bearing steel with about 0.2 per cent copper in the other. This was done with the hope that if the presence of copper in the base metal in a greater amount than that usually present in ordinary commercial steels and irons, does exert any influence upon the "life" of the galvanized product, such effect would be manifested in the test results.

One 6 by 12 inch piece (152 by $305 \mathrm{~mm}$ ) was cut from selected copper-bearing and noncopper-bearing galvanized sheets having 0.9 , 1.5 , and 2.5 ounces zinc coating, and the six pieces were annealed, at the New Jersey Zine Co.'s research laboratory, in the air for onehalf hour at $500^{\circ} \mathrm{C}$. $\left(932^{\circ} \mathrm{F}\right.$.) with the object of diffusing iron through the zinc coating and obtaining a larger proportion of the iron-zinc alloy in the coating. The annealed pieces were then cut into three 6 by $3 \frac{3}{4}$ inch (152 by $95 \mathrm{~mm}$ ) specimens for inclusion in the laboratory tests. The spangled surface of the zinc coating had been changed by the heat treatment to a smooth, fairly dark gray matte surface. Each piece gained in weight, as determined by weighing before and after the annealing treatment, by the same amount, namely, $0.014 \mathrm{oz} . / \mathrm{ft} .{ }^{2}$ of sheet $\left(0.043 \mathrm{~g} / \mathrm{dm}^{2}\right)$. A microscopic examination of the coating on these heat-treated pieces showed that it consisted mostly of the iron-zine alloy, probably $\mathrm{FeZn}_{7}$, with a narrow layer of the iron-zinc alloy, $\mathrm{FeZn}_{3}$, next to the steel base. ${ }^{12}$

\footnotetext{
12 Private communication from W. H. Finkeldey, formerly of the New Jersey Zinc Co.
} 


\begin{tabular}{|c|c|c|c|c|c|c|c|c|c|c|}
\hline \multirow{3}{*}{$\begin{array}{c}\text { Mate- } \\
\text { rial } \\
\text { No. }\end{array}$} & \multirow{3}{*}{$\begin{array}{l}\text { Source of } \\
\text { material }\end{array}$} & \multirow{3}{*}{$\begin{array}{c}\text { Labora- } \\
\text { tory } \\
\text { No. }\end{array}$} & \multirow{3}{*}{ Base metal } & \multirow{3}{*}{$\begin{array}{c}\text { Nominal } \\
\text { sheet } \\
\text { gauge }\end{array}$} & \multirow{3}{*}{ Type of zinc coating } & \multicolumn{5}{|c|}{$\begin{array}{l}\text { Weight of zinc coating in ounces per square foot of } \\
\text { sheet, as determined by- }\end{array}$} \\
\hline & & & & & & \multirow{2}{*}{$\begin{array}{l}\text { Weighing } \\
\text { method } 1\end{array}$} & \multicolumn{4}{|c|}{ Stripping test 3} \\
\hline & & & & & & & A verage & Maximum & Minimum & $\begin{array}{l}\text { Maximum } \\
\text { deviation } \\
\text { from } \\
\text { average }\end{array}$ \\
\hline $\begin{array}{l}1 \\
2 \\
3 \\
4\end{array}$ & 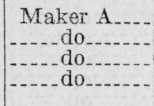 & $\begin{array}{l}\text { SH } 1 \\
\text { SH } 2 \\
\text { KH } 1 \\
\text { KH } 2\end{array}$ & $\begin{array}{l}\text { Noncopper-bearing steel } \\
\text { Copper-bearing steel }\end{array}$ & $\begin{array}{l}22 \\
22 \\
22 \\
22\end{array}$ & \begin{tabular}{|c|} 
Hot-dip galvanized..... \\
- do
\end{tabular} & $\begin{array}{l}0.83 \\
.87 \\
.91 \\
.88\end{array}$ & $\begin{array}{r}0.88 \\
.95 \\
.94 \\
.90\end{array}$ & $\begin{array}{r}0.96 \\
1.13 \\
.97 \\
.92\end{array}$ & $\begin{array}{r}0.80 \\
.89 \\
.89 \\
.87\end{array}$ & $\begin{array}{l}0.08 \\
.18 \\
.05 \\
.03\end{array}$ \\
\hline $\begin{array}{l}5 \\
6 \\
7 \\
8\end{array}$ & 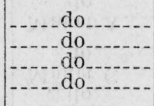 & $\begin{array}{l}\mathrm{SE} 1 \\
\mathrm{SE} 2 \\
\mathrm{KE} 1 \\
\mathrm{KE} 2\end{array}$ & $\begin{array}{l}\text { Noncopper-bearing steel } \\
\text { Copper-bearing steel }\end{array}$ & $\begin{array}{l}22 \\
22 \\
22 \\
22\end{array}$ & 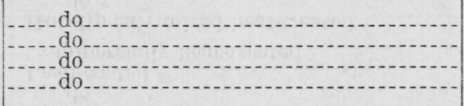 & $\begin{array}{l}1.26 \\
1.17 \\
1.19 \\
1.18\end{array}$ & $\begin{array}{l}\text { 1. } 28 \\
\text { 1. } 26 \\
\text { 1. } 26 \\
1.24\end{array}$ & $\begin{array}{l}1.43 \\
1.35 \\
1.40 \\
1.32\end{array}$ & $\begin{array}{l}1.18 \\
1.18 \\
1.18 \\
1.10\end{array}$ & $\begin{array}{l}.15 \\
.09 \\
.14 \\
.14\end{array}$ \\
\hline $\begin{array}{r}9 \\
10 \\
11 \\
12\end{array}$ & 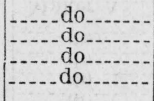 & $\begin{array}{rl}\mathrm{SC} & 1 \\
\mathrm{SC} & 2 \\
\mathrm{KC} & 1 \\
\mathrm{KC} & 2\end{array}$ & $\begin{array}{l}\text { Noncopper-bearing steel } \\
\text { Copper-bearing steel. } \\
\end{array}$ & $\begin{array}{l}22 \\
22 \\
22 \\
22\end{array}$ & 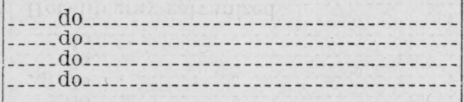 & $\begin{array}{l}1.54 \\
1.57 \\
1.50 \\
1.46\end{array}$ & $\begin{array}{l}1.63 \\
1.63 \\
1.88 \\
1.30\end{array}$ & $\begin{array}{l}1.87 \\
1.73 \\
2.84 \\
1.47\end{array}$ & $\begin{array}{r}1.48 \\
1.42 \\
1.45 \\
.92\end{array}$ & $\begin{array}{l}.24 \\
.21 \\
.96 \\
.38\end{array}$ \\
\hline $\begin{array}{l}13 \\
14 \\
15 \\
16\end{array}$ & 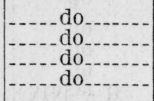 & $\begin{array}{lll}\mathrm{SB} & 1 \\
\mathrm{SB} & 2 \\
\mathrm{~KB} & 1 \\
\mathrm{~KB} & 2\end{array}$ & $\begin{array}{l}\text { Noncopper-bearing steel } \\
\text { Copper-bearing steel } \\
\end{array}$ & $\begin{array}{l}22 \\
22 \\
22 \\
22\end{array}$ & \begin{tabular}{|l|l} 
\\
\\
\end{tabular} & $\begin{array}{l}2.06 \\
2.05 \\
2.15 \\
2.09\end{array}$ & $\begin{array}{l}2.14 \\
2.14 \\
2.19 \\
2.16\end{array}$ & $\begin{array}{l}2.36 \\
2.26 \\
2.42 \\
2.53\end{array}$ & $\begin{array}{l}1.88 \\
1.99 \\
2.06 \\
1.96\end{array}$ & $\begin{array}{l}.26 \\
.14 \\
.22 \\
.38\end{array}$ \\
\hline $\begin{array}{l}17 \\
18 \\
19 \\
20\end{array}$ & 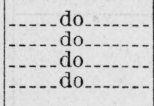 & $\begin{array}{lll}\mathrm{SA} & 1 \\
\mathrm{SA} & 2 \\
\mathrm{KA} & 1 \\
\mathrm{KA} & 2\end{array}$ & \begin{tabular}{|l} 
Noncopper-bearing steel \\
Copper-bearing steel. \\
$-d_{0}$
\end{tabular} & $\begin{array}{l}22 \\
22 \\
22 \\
22\end{array}$ & \begin{tabular}{|l|l|} 
\\
\\
\end{tabular} & $\begin{array}{l}2.54 \\
2.61 \\
2.70 \\
2.59\end{array}$ & $\begin{array}{l}2.62 \\
2.63 \\
\text { 2. } 59 \\
2.63\end{array}$ & $\begin{array}{l}3.23 \\
3.15 \\
3.10 \\
3.24\end{array}$ & $\begin{array}{l}2.36 \\
2.27 \\
2.34 \\
2.27\end{array}$ & $\begin{array}{l}.61 \\
.53 \\
.50 \\
.61\end{array}$ \\
\hline $\begin{array}{l}21 \\
22 \\
23 \\
24\end{array}$ & 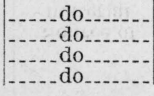 & \begin{tabular}{rr|} 
SK & 1 \\
SK & 2 \\
KK & 1 \\
KK & 2
\end{tabular} & $\begin{array}{c}\text { Noncopper-bearing steel } \\
\text { Copper-bearing steel. }\end{array}$ & $\begin{array}{l}28 \\
28 \\
28 \\
28\end{array}$ & \begin{tabular}{|l|l} 
\\
\end{tabular} & $\begin{array}{l}.83 \\
.77 \\
.83 \\
.85\end{array}$ & $\begin{array}{l}.85 \\
.80 \\
.92 \\
.93\end{array}$ & $\begin{array}{r}1.01 \\
.91 \\
1.04 \\
1.27\end{array}$ & $\begin{array}{l}.79 \\
.73 \\
.82 \\
.79\end{array}$ & $\begin{array}{l}.16 \\
.11 \\
.12 \\
.35\end{array}$ \\
\hline
\end{tabular}


TABLE 2.- Sheet materials used in simulated atmospheric corrosion and spray tests-Continued

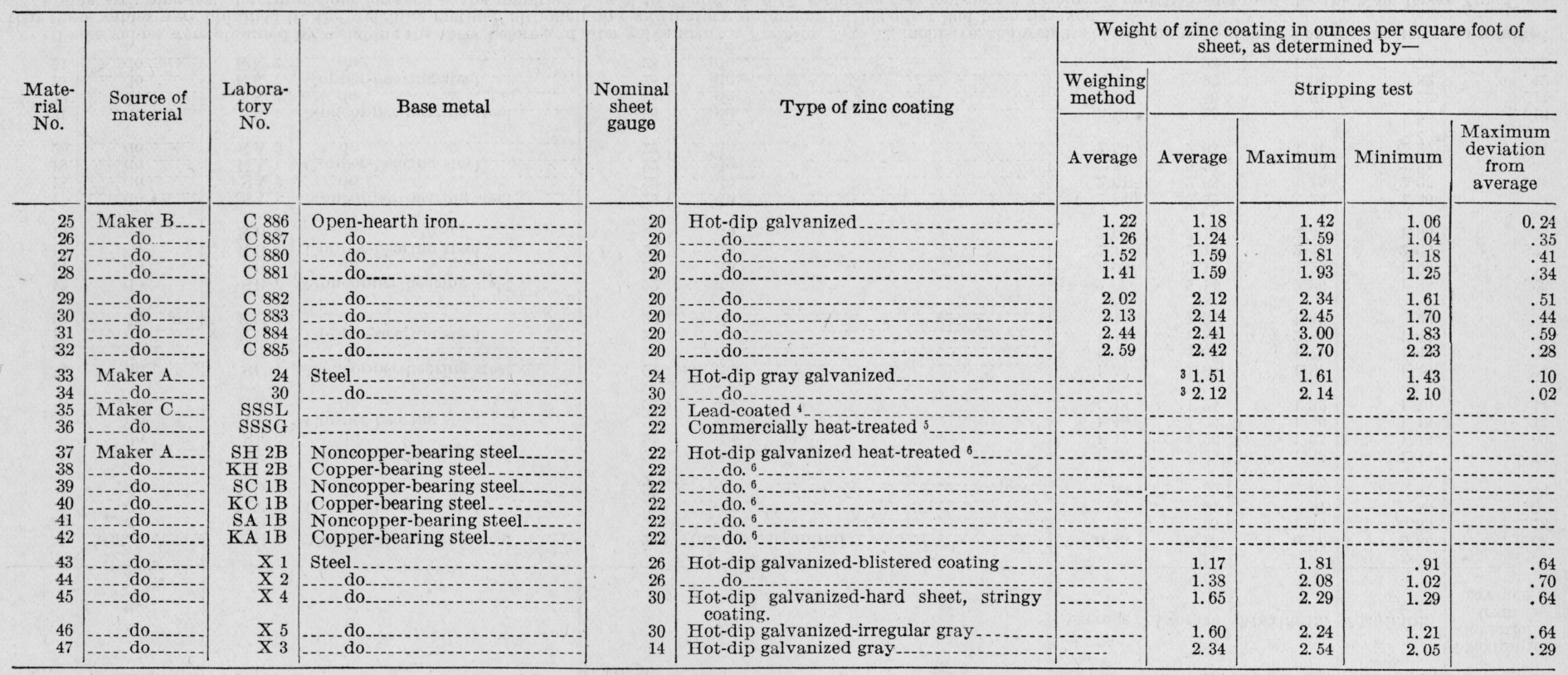

${ }^{3}$ Three stripping-test determinations of each of these two materials were made at this bureau. The $2 \frac{1}{4}$-inch square specimens were cut at random from two 30 -inch square sheets.

A miscroscopic examination of a cross section of the coated sheet revealed the presence of a thin layer lying between the base metal and the lead coat. The exact nature of this layer was not determined, but it appears probable that the sheet had been galvanized before the lead coating was applied, since the underlying surface laid bare by the blistering of

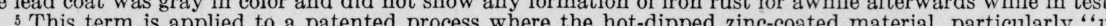

passage through the molten-zinc bath, for the purpose of making the zinc coating more uniformly distributed, increasing the proportion of the iron in the coating and following the bending qualities of the treated material. This process has also been successfully applied to sheets. 6 A piece 6 by 12 inches was cut from each of material Nos. 2, 4, 9, 11, 17, and 19, and the 6 pieces were sent to the New Jersey Zinc Co.'s research 1 ,
annealed at $500^{\circ} \mathrm{C}$. for one-half hour. After their return, they were cut up into 6 by $33 / 4$ inch specimens for inclusion in the laboratory corrosion tests. 
There were also included in these tests, as a matter of information to this bureau, specimens cut from 20 -inch $(508 \mathrm{~mm})$ square leadcoated and "commercially heat-treated" sheets, products in process of commercial development which were received from a manufacturer for this purpose.

The specimens cut from all the materials, excepting the heattreated ones just mentioned above, were 4 inches $(102 \mathrm{~mm})$ square. A $1 / 8$-inch $(3 \mathrm{~mm})$ diameter hole was drilled at the middle of and close to one edge of the specimens for suspending on glass hooks in the spray tests. A large portion of the specimens used in the simulated atmospheric corrosion tests had this hole, even though it was not needed. At the outset of the tests, a number of specimens were coated along the edges for a width of about three-sixteenths inch $(5 \mathrm{~mm})$ with one or two applications of bitumastic enamel, care being taken to include the suspension hole well within the coated area, in order that no galvanic action would occur between the zinc coating and the steel body at the cut edge. The coated specimens were kept in an electric oven at about $50^{\circ} \mathrm{C}$. $\left(122^{\circ} \mathrm{F}\right.$.) for a few hours to harden the enamel coating. This coating was found to be unsatisfactory, as it blistered and flaked off badly during the early stages of the tests. Asphalt varnish was substituted with somewhat more satisfactory results, the coating being air-dried rather than oven-dried and with two or three applications. This coating usually remained quite adherent and continuous for a fairly large number of cycles. No attempt was made to recoat the specimens during the progress of the test, as the coating on the edges of the specimens appeared to be quite intact, and any rusting that may have occurred along the edges did not interfere with the results observed on the faces of the specimens. After the experimental work described in this paper had been completed, some tests were made with vulcalock rubber cement and with a mixture of this cement and aluminum powder for coating the cut edges of galvanized sheets. It had been found at this bureau recently that, when applied as a protective coating to metal surfaces, the latter showed very satisfactory protective qualities, and the former but a short-lived resistance, during long-continued exposures in a laboratory weathering test, wherein the specimens were subjected to repeated cycles of exposure to $(a)$ a vigorous water spray, $(b)$ the rays of a carbon arc light, $(c)$ a freezing temperature, and $(d)$ an ozonized atmosphere. When applied as a thin, smooth covering along the edges of the galvanized sheet specimens, these two types of coating were found to stand up very well, especially the rubber cement alone, in the simulated atmospheric corrosion, sodium chloride spray, and ammonium chloride spray tests. Both showed good adherence and no signs of cracking or peeling off at the stage where the asphalt-varnish coating on other specimens included in the test had already blistered and flaked off to a large extent. 


\section{EXPERIMENTAL METHODS}

I(a) SIMULATED ATMOSPHERIC CORROSION TEST

This test was carried out in 24-hour cycles, each cycle consisting of three stages:

1. Exposure to a muggy, corroding atmosphere, consisting by volume or 94 parts air, 5 parts carbon dioxide gas, and 1 part sulphur dioxide gas and saturated with water vapor, for five hours.

2. Exposure to a water spray for one hour, wherein the corrosion products formed were washed off in a manner similar to the action of the rain.

3. Drying period of 18 hours, during which the specimens became thoroughly dried by exposure to the room atmosphere of the laboratory, and the rebuilding of the protective film on the zinc coating destroyed in the first stage was thus promoted.

The cycles were continued until the failure of the zinc coating on one face, and on both faces in most cases, of the specimens was clearly manifested by the formation of red-brown colored rust at the point where the steel or iron base was laid bare. The lengths of time for the first two stages were arbitrarily chosen, although in the same ratio as in the New Jersey Zinc Co. tests, in order that these stages could be carried out to completion within the limits of the workingday. Oftentimes one and even several days elapsed between successive cycles, so the length of exposure of the specimens to the room atmosphere varied, but probably little or no marked change in the surface conditions of the specimens occurred in the interval between the 18-hour drying period and the start of the next cycle.

The apparatus employed in this work is shown in Figures 1,2, and 3. The test was carried out in two wooden containers, $\bar{K}$, one of which served as the "tank" and the other as the cover to the tank by being placed on top and in an inverted position. The containers were of cypress wood and of a variety which may be found in most any household-furnishings store. Their dimensions were $291 / 2$ inches $(750 \mathrm{~mm})$ in diameter at the open end, 271/4 inches $(692 \mathrm{~mm})$ in diameter at the closed end, and $141 / 2$ inches $(368 \mathrm{~mm}$ ) in height.

At the start of the first stage of the test, the tank was filled with hot water up to a definite height. Next, a circular false bottom, $F$, 26 inches $(660 \mathrm{~mm})$ in diameter and made from a board $11 / 8$ inches $(29 \mathrm{~mm})$ thick, was placed upon four $1 \frac{1}{4}$-inch $(32 \mathrm{~mm})$ square wooden uprights, $U$, being at a short distance above the water level when in position. A glass tube, serving as a gas inlet, was then placed in position as indicated in Figure 2. The specimen holder, $S H$, which was in two separate parts, each consisting of four wooden semiannular rings held in position by a wooden strip extending along at approximately the diameter of the rings (see fig. 3), was next laid on 
B. S. Journal of Research, RP10

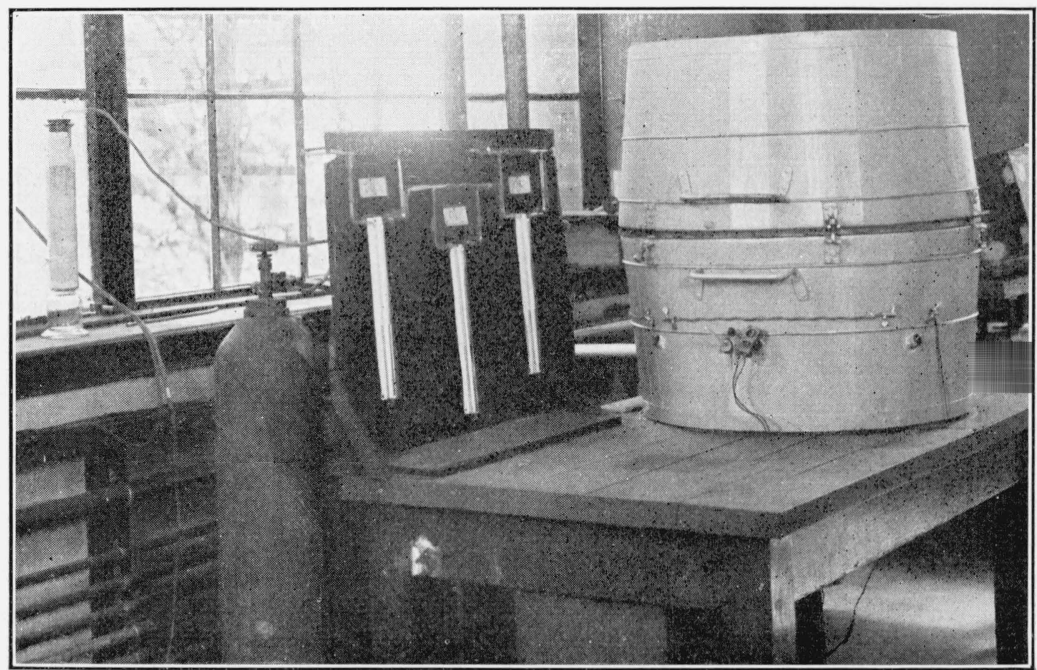

FIG. 1.-Simulated atmospheric corrosion test apparatus, shown as assembled 
B. S. Journal of Research, RP10

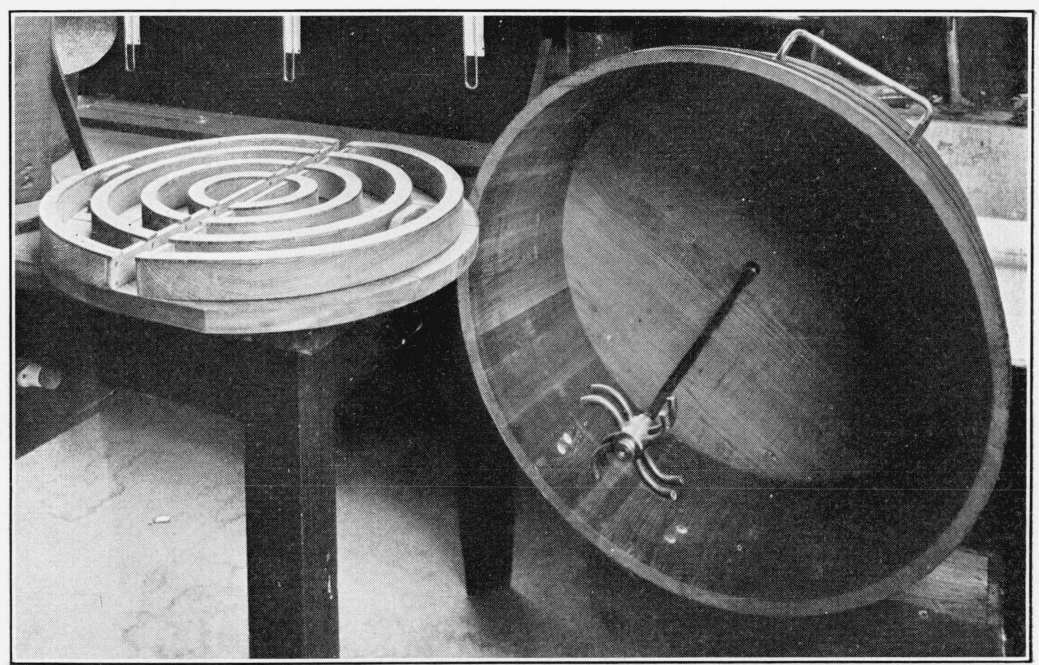

FIG. 3.-Water-spraying arrangement and specimen racks for simulated atmospheric corrosion test apparatus 

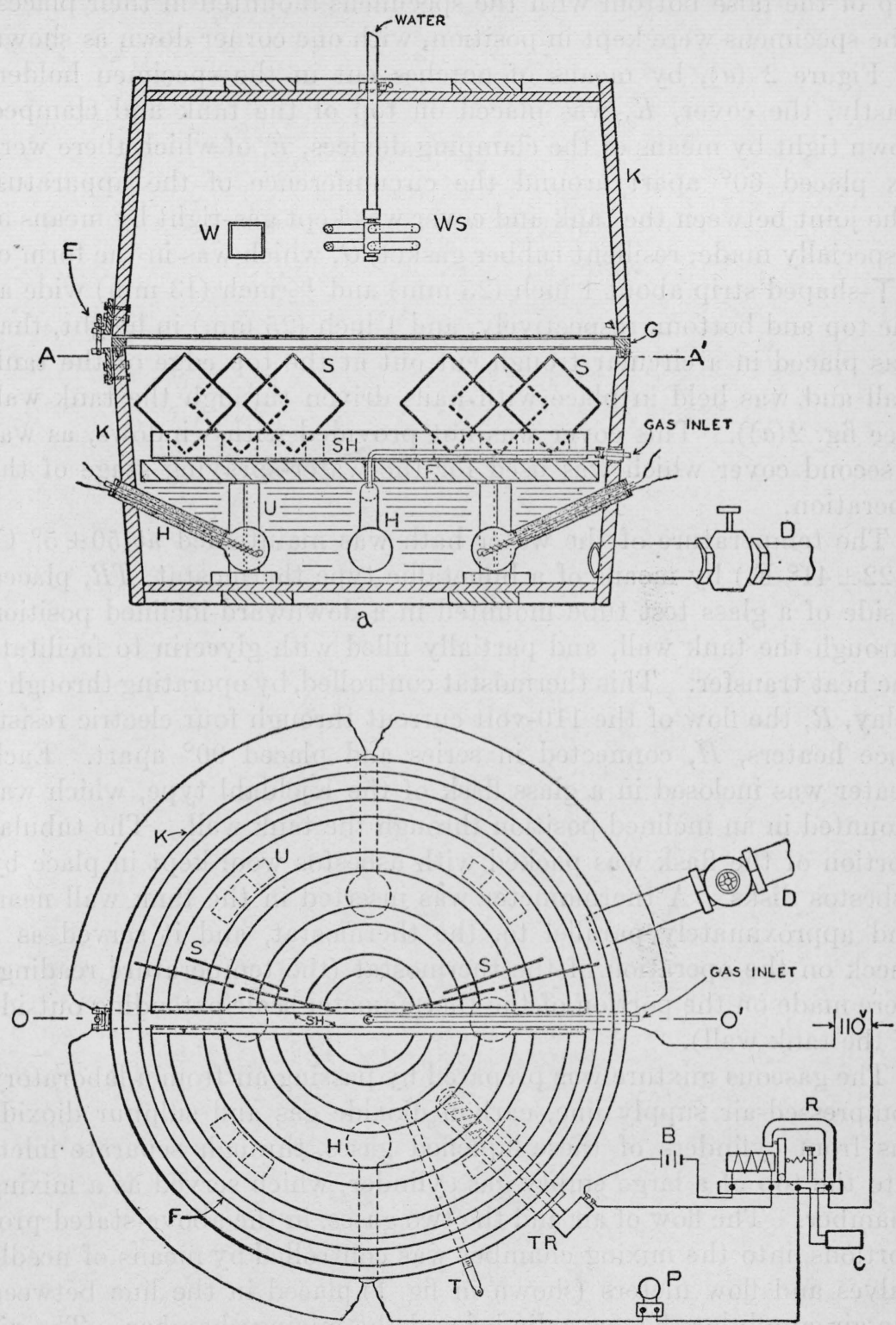

b

FIG. 2.-Details of simulated atmospheric corrosion test apparatus

$a$, vertical section at $O-O^{\prime}$; the cover shown here was that used in the water-spraying stage of the operation; $b$, plan below horizontal plane $A-A^{\prime}$ : The wiring arrangement is shown at lower right; $W S$, water sprinkler; $W$, window; $S$, specimens; $S H$, specimen holder; $F$, false bottom; $H$, electrical heater; $D$, drain pipe; $U$, supports for false bottom and specimen holders; $T$, thermometer; $T R$, thermoregulator; $R$, relay; $P$, pilot light; $B$, battery; $C$, condenser; $K$, wooden container; $E$, clamping arrangement; $G$, rubber gasket 
top of the false bottom with the specimens mounted in their places. The specimens were kept in position, with one corner down as shown in Figure $2(a)$, by means of notches cut in the specimen holder. Lastly, the cover, $K$, was placed on top of the tank and clamped down tight by means of the clamping devices, $E$, of which there were six placed $60^{\circ}$ apart around the circumference of the apparatus. The joint between the tank and cover was kept gas-tight by means of a specially made, resilient rubber gasket, $G$, which was in the form of a T-shaped strip about 1 inch $(25 \mathrm{~mm})$ and $1 / 2$ inch $(13 \mathrm{~mm})$ wide at the top and bottom, respectively, and 1 inch $(25 \mathrm{~mm}$ ) in height, that was placed in a circular trough cut out at the top edge of the tank wall and was held in place with nails driven through the tank wall (see fig. $2(a)$ ). This cover was not provided with windows, as was a second cover which was used for the water-spraying stage of the operation.

The temperature of the water bath was maintained at $50 \pm 5^{\circ} \mathrm{C}$. $\left(122 \pm 41^{\circ}\right.$ F.) by means of a bimetallic type thermostat, $T R$, placed inside of a glass test tube mounted in a downward-inclined position through the tank wall, and partially filled with glycerin to facilitate the heat transfer. This thermostat controlled, by operating through a relay, $R$, the flow of the 110-volt current through four electric resistance heaters, $H$, connected in series and placed $90^{\circ}$ apart. Each heater was inclosed in a glass flask of the Kjeldahl type, which was mounted in an inclined position through the tank wall. The tubular portion of the flask was packed with asbestos wool kept in place by asbestos disks. A thermometer was inserted in the tank wall near, and approximately parallel to, the thermostat, and it served as a check on the operation of the thermostat (the temperature readings were made on the portion of the thermometer scale extending outside of the tank wall).

The gaseous mixture was prepared by passing air from a laboratory compressed-air supply line, carbon dioxide gas and sulphur dioxide gas from cylinders of these liquefied gases, through separate inlets into the top of a large empty gas cylinder, whicb served as a mixing chamber. The flow of air and the two gases, in the above-stated proportions, into the mixing chamber was controlled by means of needle valves and flow meters (shown in fig. 1) placed in the line between the air supply or the gas cylinder and the mixing chamber. The air was passed, on its way to the flow meter, through a large drying tower filled with soda lime to remove any carbon dioxide present. Concentrated sulphuric acid was used as the liquid in the flow meters. The resulting gaseous mixture was passed out through the bottom of the mixing chamber and into the testing apparatus. The terminus of 
the gas-inlet tube on the tank was situated beneath the false bottom, as shown in Figure $2(a)$, so that the incoming stream of gaseous mixture would come directly upon the surface of the warm water and spread radially to the edge of the false bottom, upward along the tank walls and into the specimen chamber. Thus, the specimens were exposed to a corroding atmosphere under "muggy" conditions.

The proportions of the $\mathrm{CO}_{2}$ and $\mathrm{SO}_{2}$ in the gaseous mixture would, of course, be considerably altered during the early part of the first stage, since the large volume of air present in the apparatus at the outset would dilute the gaseous mixture, and, furthermore, $\mathrm{SO}_{2}$ is readily soluble in water, much more so in cold water than in hot, and thus a considerable portion of it in the incoming gas would be absorbed by the water bath until the saturation point of the water for $\mathrm{SO}_{2}$ and $\mathrm{CO}_{2}$ was reached. No attempts were made to determine the composition of the gaseous mixture inside the test apparatus during the progress of the first stage, as a study of the various details and refinements of the test methods did not come within the scope of this investigation. The gas outlet was placed at about 3 inches $(76 \mathrm{~mm})$ below the top of the cover (this is shown at the left edge of the cover in fig. 1), and the outgoing gaseous mixture was passed through rubber tubing into the air outside of a window.

At the completion of the first stage the cover was unclamped and removed after the gaseous mixture in the apparatus had been blown out through the exit tubing by a blast of air for about half an hour. The water in the tank was drained by opening the gate valve of the drain pipe $(D$, fig. $2(a))$, which was left open for the remainder of the cycle. A second cover, provided with a water sprinkler and two small glass windows placed diametrically opposite (WS and $W$, figs. 2 (a) and 3 ; the windows were inserted in the cover after the photograph for fig. 3 had been taken), was clamped onto the tank. Water was admitted to the sprinkler through the top of the sprinkler pipe at a rate slow enough so that a steady, fairly fast falling shower of water drops would be directed toward the underlying cluster of specimens throughout the second stage. The windows proved to be useful, for the pressure in the water line varied so that the sprinkler stopped functioning occasionally.

When the second stage was completed, the cover was removed and the specimen holders with the specimens in place were taken out of the tank. After being brushed with a stiff bristle brush under a stream of tap water to remove any adhering corrosion products, the specimens were put back in their places on the specimen holders, and the latter were either put back into the tank or placed on a near-by laboratory table for the third, or drying, stage.

$109748^{\circ}-28-3$ 
(b) SPRAY TESTS

The apparatus employed in the spray tests is shown in Figure 4(a). The outside dimensions of the two Alberene stone boxes were 32 by $161 / 2$ by 12 inches ( 813 by 419 by $305 \mathrm{~mm}$ ) in height, and the walls were $1 \frac{1}{4}$ inches $(32 \mathrm{~mm})$ thick. A piece of plate glass served as the top cover, $D$, and permitted ready observation of the progress of the test. The specimens were suspended from glass rods, extending across inside the box, by means of glass hooks passing through a hole, $1 / 8$-inch $(3 \mathrm{~mm})$ diameter, at the middle of one edge of the specimen (these details are not shown in Figure $4(a)$. The corrodent was

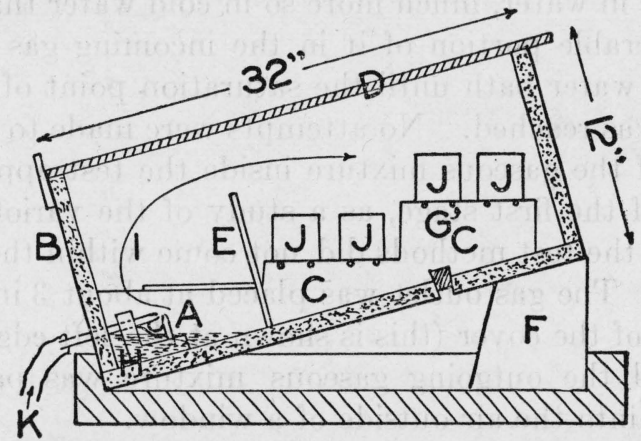

Fig. 4 (a).-Details of spray box

$B$, Alberene stone box; $A$, atomizer; $H$, corrosive solution; $K$, compressed air stream; $E$, baffle plates; $I$, course of spray; $D$, glass cover; $J$, specimens; $F$, support for box
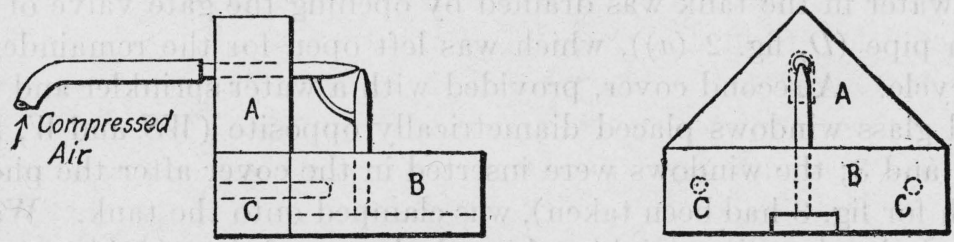

FIG. 4 (b).-Details of atomizer used in spray box (a)

The atomizer consists of two nipples, made from glass tubing and joined at right angles by a glass rib, and is mounted in an alberene stone frame. The corrosive solution is sucked up through the vertical nipple by the air stream

Parts $A$ and $B$ of the frame are fastened together with wooden plugs, $C$

atomized, by means of the device shown in Figure $4(b)$, into a fog or fine mist which completely filled the specimen chamber. A stream of compressed air at 7 to 10 pounds pressure was used in atomizing the solution; the precaution was taken to remove any oil present by passing the air stream through a short length of a 2-inch diameter iron pipe filled with absorbent cotton. The baffle plates, $E$, served to protect the specimens from direct exposure to the stream of spray issuing from the atomizer and to swirling currents in the mist; the vertical baffle plate served also as a "dam" which prevented the condensed spray, containing the corrosion products from the specimens, from flowing back to the reservoir of solution, $H$. This res- 
ervoir was at all times maintained at a level high enough for the efficient operation of the atomizer. The consumption of the corrodent amounted to about $1 / 2$ liter per 24 hours.

Sodium chloride and ammonium chloride solutions of $1 \mathrm{~N}$ strength (containing 5.65 per cent $\mathrm{NaCl}$ and 5.35 per cent $\mathrm{NH}_{4} \mathrm{Cl}$ by weight, respectively) were chosen for these spray tests, as they were of intermediate strength. The test with one solution was carried out in one box and that with the other simultaneously in another box. Both boxes were connected to the same air supply.

This form of test used with sodium chloride solution, usually a concentrated one (containing 20 per cent sodium chloride salt by weight), has been rather widely employed for testing all types of protective coatings, more particularly zinc coatings. It has been subjected to many criticisms, especially with respect to the lack of discrimination shown in bringing out thin spots in the coating and in the unsatisfactory differentiating between zinc coatings of generally similar nature and quality. It has, however, been considered useful by many in determining the relative value of coatings for marine or seacoastal exposure.

Farnsworth and Hocker ${ }^{13}$ found in some tests, carried out by the intermittent-immersion method of testing, on iron specimens electroplated with zinc that a 2 per cent solution of ammonium chloride attacks and removes the zinc-corrosion products from the surface of the specimen without producing any or only a very slow action on the zinc metal, since the surface of the specimen and the salt solution remained clear of undissolved corrosion products. The addition of a small amount of an oxidizing agent to the salt solution produced a relatively more rapid action. They also noted that in a comparative test, carried out at $22^{\circ} \mathrm{C}$. ( $\left(72^{\circ} \mathrm{F}\right.$.) for $331 / 2$ hours, zinc continuously immersed in an aerated 2 per cent sodium chloride solution suffered a rate of attack, as determined by the rate of loss in weight, about one-third as fast as that in aerated ammonium chloride solution of the same strength. Results obtained at this bureau have shown that zinc on plated and "hot-dipped" sheets is not removed by immersion in a solution of salt $(\mathrm{NaCl})$ nearly so rapidly as it is by a spray of the same solution.

\section{EXPERIMENTAL RESULTS}

The results for the simulated atmospheric corrosion test are tabulated in Table 3 and summarized in Figure 5 (Tables 3 and 4 have been included in this paper for the benefit of those desiring to make a more detailed analysis of the test data). There are given in this table

\footnotetext{
${ }^{13}$ Farnsworth, F. F., and Hocker, C. D., "An intermittent-immersion test as an aid in evaluating zinc coats plated on iron and steel," Tr. Am. Electrochem. Soc., 45 p. 281; 1924.
} 
the number of cycles, for both faces of each specimen, which were required to produce the first clearly defined indications that the coating had broken down as shown by the formation of a red-brown rust on the steel or iron base thus laid bare. In reaching the point of failure the second face of the specimen lagged behind the first face by one cycle in about 25 per cent of the cases and by two or more cycles in about 45 per cent of the cases. This is not surprising, for the thickness of the coating may not be quite the same on opposite surfaces of the sheet and even at different portions of the same surface. The

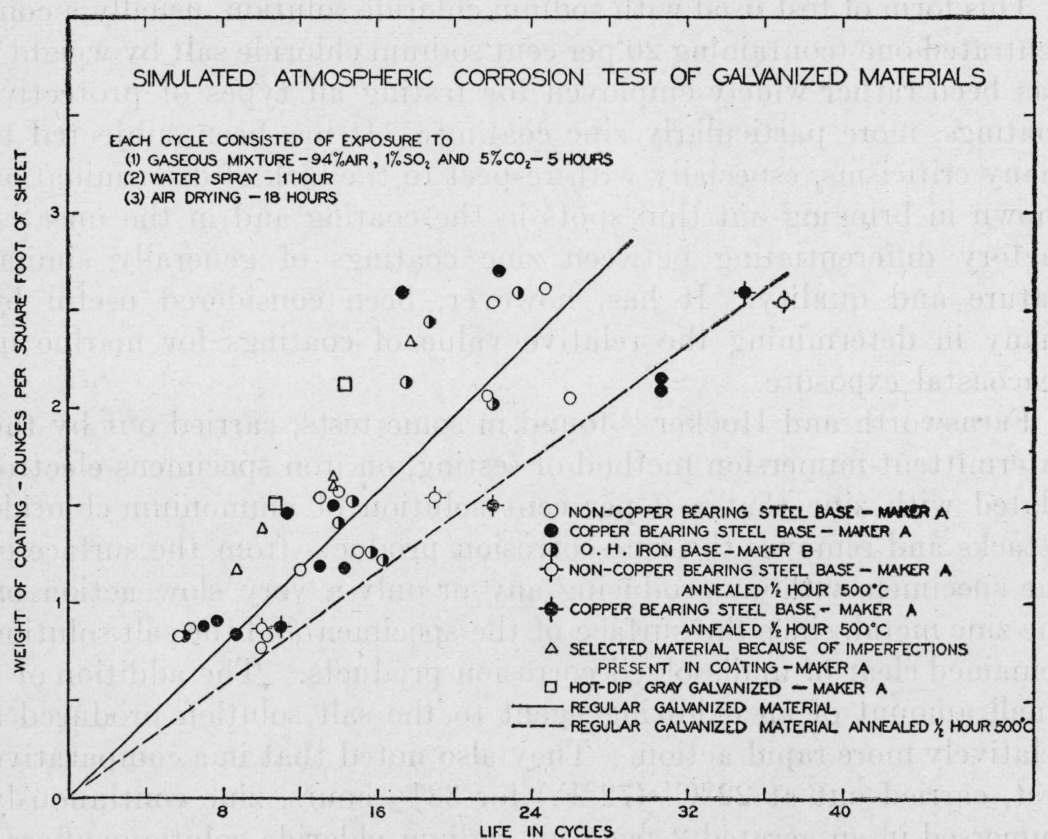

FIG. 5.-Results of simulated atmospheric corrosion tests

Each point plotted in the diagram is the average value of three determinations

average values for the face (face No. 1) of the specimen, which first reached the failure point have been plotted in Figure 5 for the different test materials. Each point plotted represents the average of three determinations, which were made at the same time and under the same conditions. Although the plotted data show a considerable scattering, the solid line, which has been drawn in as nearly a mean position as practicable (with reference to all uncrossed circles), indicates the relation between the "life" of the coating, expressed in cycles, and the weight of the coating in oz./ft. ${ }^{2}$ of sheet; for example, a coating of $2.0 \mathrm{oz}$. $/ \mathrm{ft}^{2}{ }^{2}$ of sheet should require 20 or 21 cycles of exposure, under the conditions of the experiment, for the coating to break down. 


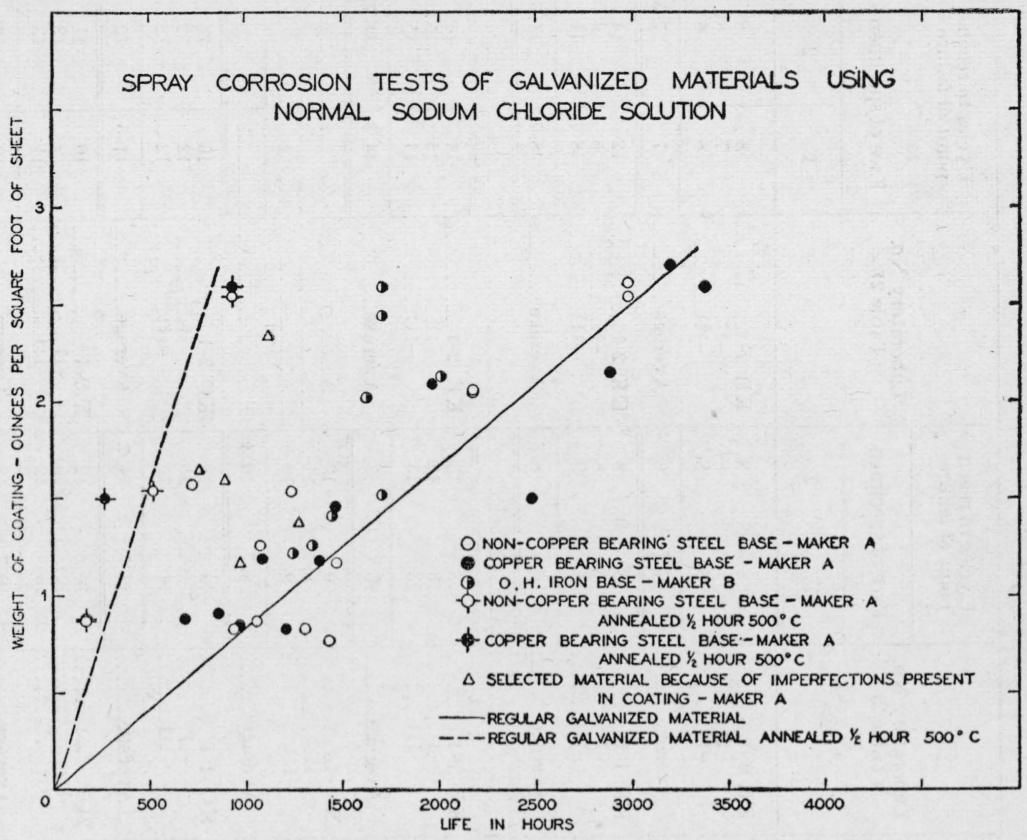

FIG. 6.-Results of spray tests with $N$ sodium chloride solution

Each point plotted in the diagram is the average value of three determinations

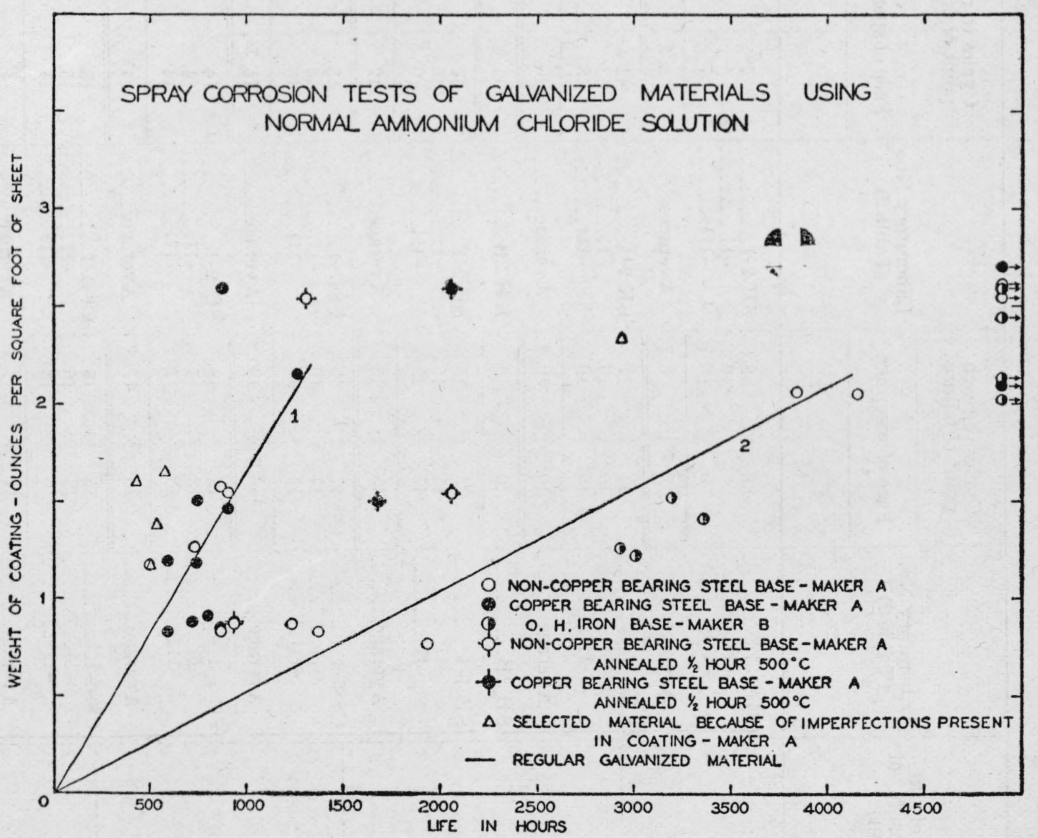

Fig. 7.-Results of spray tests with $N$ ammonium chloride solution

Each point plotted in the diagram is the average value of three determinations. The results represented by curves 2 and 1 were influenced by the fact that the simulated atmospheric corrosion test was run, and was not run, respectively, simultaneously with and in close proximity to the spray test 
TABLE 3.-Results of simulated atmospheric corrosion test

\begin{tabular}{|c|c|c|c|c|c|c|c|c|c|c|c|c|}
\hline \multirow{3}{*}{$\begin{array}{l}\text { Weight of zinc } \\
\text { coating (oz./ft. }{ }^{2} \text { of } \\
\text { sheet) }\end{array}$} & \multirow{3}{*}{$\begin{array}{l}\text { Laboratory No. } \\
\text { (Table 2) }\end{array}$} & \multirow{2}{*}{\multicolumn{2}{|c|}{$\begin{array}{l}\begin{array}{l}\text { Cycles to reach } \\
\text { point of failure }\end{array} \\
\text { Face of specimen }\end{array}$}} & \multirow{3}{*}{$\begin{array}{l}\text { Laboratory No. } \\
\text { (Table 2) }\end{array}$} & \multirow{2}{*}{\multicolumn{2}{|c|}{$\begin{array}{l}\text { Cycles to reach } \\
\text { point of failure }\end{array}$}} & \multirow{3}{*}{$\begin{array}{l}\text { Laboratory No. } \\
\quad \text { (Table 2) }\end{array}$} & \multirow{2}{*}{\multicolumn{2}{|c|}{$\begin{array}{l}\begin{array}{l}\text { Cycles to reach } \\
\text { point of failure }\end{array} \\
\text { Face of specimen }\end{array}$}} & \multirow{3}{*}{$\begin{array}{l}\text { Laboratory No. } \\
\text { (Table 2) }\end{array}$} & \multirow{2}{*}{\multicolumn{2}{|c|}{$\begin{array}{l}\text { Cycles to reach } \\
\text { point of failure }\end{array}$}} \\
\hline & & & & & & & & & & & & \\
\hline & & 1 & 2 & & 1 & 2 & & 1 & 2 & & 1 & 2 \\
\hline \multirow{7}{*}{$0.75-1.0 \ldots$} & $\left(\begin{array}{r}\text { SH } 1-1 \ldots \ldots \\
-11 \\
\\
-111 \ldots\end{array}\right.$ & $\begin{array}{r}6 \\
6 \\
5 \\
\end{array}$ & $\begin{array}{r}18 \\
6 \\
6\end{array}$ & $\begin{array}{r}\text { SH } 2-1 \ldots \ldots \\
\quad-11 \\
\quad-111 \ldots\end{array}$ & $\begin{array}{l}7 \\
5 \\
7\end{array}$ & $\begin{array}{l}9 \\
5 \\
9\end{array}$ & \multirow{5}{*}{$=\begin{array}{r}\text { KH } 1-1 \\
-11 \\
-111 \\
\text { Average............... } \\
\text { KK 1-1 } \\
-11 \\
-111 \ldots \\
\text { Average }\end{array}$} & $\begin{array}{l}8 \\
7 \\
8\end{array}$ & $\begin{array}{l}8 \\
8 \\
8\end{array}$ & \multirow{2}{*}{$\begin{array}{r}\text { KH } 2-1 \\
-11 \\
-111 \\
\text { Average }\end{array}$} & $\begin{array}{l}8 \\
7 \\
6\end{array}$ & $\begin{array}{l}8 \\
8 \\
6\end{array}$ \\
\hline & Average & 5.7 & 6.7 & A verage & 6.3 & 7.7 & & 7.7 & 8 & & 7 & 7.3 \\
\hline & $\left\{\begin{array}{r}\text { SK } 1-1 \ldots \ldots \\
-11 \ldots \\
-111 \ldots\end{array}\right.$ & $\begin{array}{l}11 \\
10 \\
10 \\
\end{array}$ & $\begin{array}{l}11 \\
10 \\
10 \\
\end{array}$ & \multirow{2}{*}{$\begin{array}{r}\text { SK } 2-1 \\
-11 \\
-111 \\
\text { Average }\end{array}$} & $\begin{array}{l}11 \\
11 \\
8\end{array}$ & $\begin{array}{c}11 \\
12 \\
9\end{array}$ & & $\begin{array}{l}8 \\
6 \\
4 \\
\end{array}$ & $\begin{array}{l}8 \\
8 \\
9 \\
9\end{array}$ & $\begin{array}{r}\text { KK } 2-1 \\
\quad-11 \\
-111\end{array}$ & $\begin{array}{r}12 \\
6 \\
8\end{array}$ & $\begin{array}{r}14 \\
9 \\
11\end{array}$ \\
\hline & Average & 10.3 & 10.3 & & 10 & 10.7 & & 6 & 8.3 & \multirow[t]{2}{*}{ Average } & 8.7 & 11.3 \\
\hline & (SH $2 \mathrm{~B} \ldots . .$. & 10 & 13 & $\mathrm{KH} 2 \mathrm{~B}$ & 11 & 11 & & $\ldots \ldots$ & $\ldots$ & & $\ldots$ & $\overline{\ldots \ldots \ldots}$ \\
\hline & $\left(\begin{array}{r}\text { SE } 1-1 \ldots \ldots \\
-11 \ldots \\
-111 \ldots\end{array}\right.$ & $\begin{array}{l}15 \\
15 \\
15\end{array}$ & $\begin{array}{l}15 \\
15 \\
15\end{array}$ & $\begin{array}{rl}S E & 2-1 \\
-11 \\
-111\end{array}$ & $\begin{array}{l}12 \\
15 \\
9\end{array}$ & $\begin{array}{l}14 \\
15 \\
10 \\
\end{array}$ & KE $\begin{aligned} 1-1 \ldots \ldots \\
-11 \\
\\
-111 \ldots . . .\end{aligned}$ & $\begin{array}{l}13 \\
13 \\
13\end{array}$ & $\begin{array}{l}13 \\
13 \\
13\end{array}$ & \multirow{2}{*}{$\begin{array}{r}\text { KE } 2-1 \\
-11 \\
-111 \\
\text { A verage }\end{array}$} & $\begin{array}{l}14 \\
15 \\
14 \\
\end{array}$ & $\begin{array}{l}14 \\
15 \\
15 \\
\end{array}$ \\
\hline & Average & 15 & 15 & Average-.-- & 12 & 13 & Average & 13 & 13 & & 14.3 & 14.7 \\
\hline \multirow[t]{4}{*}{$1.25 \ldots$} & $\begin{array}{r}\text { C886-1 } \\
-11 \\
-111\end{array}$ & $\begin{array}{l}17 \\
17 \\
15 \\
\end{array}$ & $\begin{array}{l}19 \\
19 \\
19 \\
\end{array}$ & $\begin{array}{r}\text { C887-1 } \\
-11 . \ldots \\
-111 . . . \\
\end{array}$ & $\begin{array}{l}15 \\
16 \\
16 \\
\end{array}$ & $\begin{array}{l}18 \\
24 \\
18 \\
\end{array}$ & $\begin{array}{r}X \quad 1-1 \\
\quad-11 \\
\quad-111\end{array}$ & $\begin{array}{l}9 \\
8 \\
9 \\
\end{array}$ & $\begin{array}{l}10 \\
11 \\
10 \\
\end{array}$ & & $\overline{c o . . .}$ & - \\
\hline & Average.... & 16.3 & 19 & Average & 15.7 & 20 & Average & 8.7 & 10.3 & & $\ldots \ldots$ & $\ldots \ldots$ \\
\hline & $\left(\begin{array}{rr}S C & 1-1 \ldots \\
-111 \ldots \\
& -111 \ldots\end{array}\right.$ & \begin{tabular}{|l|l|}
13 \\
13 \\
13 \\
\end{tabular} & $\begin{array}{l}18 \\
17 \\
17 \\
\end{array}$ & $\begin{array}{r}\text { SC } 2-1 \ldots \\
\quad-11 \\
\quad-111\end{array}$ & $\begin{array}{l}14 \\
14 \\
14 \\
\end{array}$ & $\begin{array}{l}16 \\
18 \\
17\end{array}$ & KC $\begin{aligned} 1-1 \\
-11 \\
\\
-111\end{aligned}$ & $\begin{array}{l}13 \\
14 \\
14\end{array}$ & $\begin{array}{l}13 \\
15 \\
16\end{array}$ & $\begin{array}{r}\text { KC } 2-1 \ldots . \\
-11-. \\
-111 . .\end{array}$ & $\begin{array}{l}10 \\
12 \\
12\end{array}$ & $\begin{array}{l}12 \\
12 \\
12\end{array}$ \\
\hline & A verage & 13 & 17.3 & Average & 14 & 17 & A verage & 13.7 & 14.7 & \multirow{2}{*}{$\begin{array}{r}\text { A verage } \\
\text { X } 2-11 \\
\quad-11 \\
-111 \\
\end{array}$} & 11.3 & 12 \\
\hline \multirow[t]{2}{*}{$1.5 \ldots$} & $\left\{\begin{array}{r}C 880-1 \ldots \ldots \\
-11 \ldots \\
-111 \ldots\end{array}\right.$ & $\begin{array}{l}15 \\
13 \\
16\end{array}$ & $\begin{array}{l}18 \\
16 \\
18 \\
\end{array}$ & $\begin{array}{r}\text { C881-1........... } \\
-1111 . . . . . . . \\
-111\end{array}$ & $\begin{array}{l}13 \\
15 \\
14\end{array}$ & $\begin{array}{r}121 \\
17 \\
16\end{array}$ & $\begin{array}{r}24-1 \\
-11 \\
-111 \\
-\end{array}$ & $\begin{array}{l}10 \\
12 \\
10\end{array}$ & $\begin{array}{l}12 \\
15 \\
12\end{array}$ & & $\begin{array}{r}10 \\
9 \\
11 \\
\end{array}$ & $\begin{array}{l}11 \\
12 \\
13\end{array}$ \\
\hline & A verage..... & 14.7 & 17.3 & A verage........ & 14 & 18 & A verage......... & 10.7 & 13 & A verage......... & 10 & 12 \\
\hline
\end{tabular}




\begin{tabular}{|c|c|c|c|c|c|c|c|c|c|c|c|c|}
\hline \multirow[t]{2}{*}{$1.5 \ldots$} & $\left\{\begin{array}{r}\mathrm{X} 4-1 \\
-11 \\
-111\end{array}\right.$ & $\begin{array}{l}14 \\
14 \\
13\end{array}$ & $\begin{array}{l}15 \\
14 \\
15\end{array}$ & \multirow{2}{*}{ 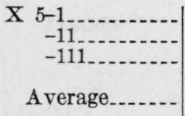 } & $\begin{array}{l}12 \\
13 \\
16\end{array}$ & $\begin{array}{l}13 \\
14 \\
17\end{array}$ & \multirow{2}{*}{ 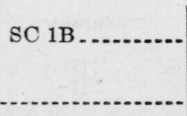 } & 19 & 22 & \multirow[t]{2}{*}{$\mathrm{KC} 1 \mathrm{~B}$} & 22 & (2) \\
\hline & A verage... & 13. 7 & 14.7 & & 13.7 & 14. 7 & & . & & & 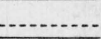 & ...... \\
\hline & 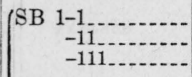 & $\begin{array}{l}26 \\
22 \\
17\end{array}$ & $\begin{array}{l}27 \\
24 \\
17\end{array}$ & $\begin{array}{r}\text { SB } 2-1 \\
-11 \\
\\
-111\end{array}$ & $\begin{array}{l}27 \\
24 \\
27\end{array}$ & $\begin{array}{l}27 \\
26 \\
28\end{array}$ & 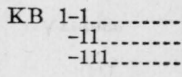 & $\begin{array}{l}30 \\
31 \\
31\end{array}$ & $\begin{array}{l}30 \\
34 \\
32\end{array}$ & KB $\begin{array}{r}2-1 \\
\quad-11 \\
\\
\quad-111\end{array}$ & $\begin{array}{l}34 \\
31 \\
27\end{array}$ & $\begin{array}{l}37 \\
33 \\
30\end{array}$ \\
\hline & Average.. & 21.7 & 22.7 & A verage.. & 26 & 27 & Average......... & 30.7 & 32 & Average & 30.7 & 33.3 \\
\hline $2.0 \ldots$ & $\begin{array}{r}\text { C882-1 } \\
-11 \\
-111 \\
\end{array}$ & $\begin{array}{l}19 \\
25 \\
22\end{array}$ & $\begin{array}{l}25 \\
31 \\
23\end{array}$ & $\begin{array}{r}\text { C883-1 } \\
-11 \\
-111 \\
\end{array}$ & $\begin{array}{l}20 \\
15 \\
(3)\end{array}$ & $\begin{array}{l}21 \\
20 \\
(3)\end{array}$ & $\begin{array}{r}30-1 \\
-11 \\
-111\end{array}$ & $\begin{array}{l}13 \\
16 \\
14 \\
\end{array}$ & $\begin{array}{l}18 \\
16 \\
16\end{array}$ & & - n & - \\
\hline & Average.... & 22 & 26.3 & A verage... & 17.5 & 20.5 & A verage...... & 14.3 & 16.7 & & n...... & .... \\
\hline & $\left(\begin{array}{r}\text { SA } 1-1 \\
\quad-11 \\
\\
-111\end{array}\right.$ & $\begin{array}{l}28 \\
20 \\
18\end{array}$ & $\begin{array}{l}31 \\
23 \\
27\end{array}$ & SA $2-1, \ldots . . . .$. & $\begin{array}{l}24 \\
26 \\
24\end{array}$ & $\begin{array}{r}38 \\
142 \\
32\end{array}$ & KA $\begin{aligned} & 1-1 \\
& \quad-11 \\
&-111 . . .\end{aligned}$ & $\begin{array}{l}22 \\
23 \\
22\end{array}$ & $\begin{array}{l}22 \\
25 \\
27\end{array}$ & KA $\begin{aligned} & 2-1 \\
& \quad-11 \\
&-111\end{aligned}$ & $\begin{array}{l}16 \\
18 \\
18\end{array}$ & $\begin{array}{l}23 \\
19 \\
18\end{array}$ \\
\hline & A verage_.... & 22 & 27 & Average.... & 24.7 & 37.3 & A verage.... & 22.3 & 24.7 & Average_......... & 17.3 & 20 \\
\hline $2.5 \ldots$ & $\left\{\begin{array}{r}\mathrm{C} 884-1 \\
-11 \\
-111 . . .\end{array}\right.$ & $\begin{array}{l}20 \\
17 \\
19\end{array}$ & $\begin{array}{l}30 \\
23 \\
24\end{array}$ & $\begin{array}{r}\text { C885-1 } \\
-11 . \\
-111 .\end{array}$ & $\begin{array}{l}20 \\
25 \\
25\end{array}$ & $\begin{array}{l}25 \\
25 \\
30\end{array}$ & $\begin{array}{r}\text { X } 3-1 \ldots \\
\quad-11 \\
-111\end{array}$ & $\begin{array}{l}18 \\
18 \\
17\end{array}$ & $\begin{array}{l}22 \\
20 \\
17\end{array}$ & SA $1 B \ldots$ & 37 & 37 \\
\hline & A verage & 18.7 & 25.7 & Average & 23.3 & 26.7 & A verage..... & 17.7 & 19.7 & & & $\cdots$ \\
\hline & (KA $2 B$ & 35 & 38 & & $\cdots$ & $\cdots$ & & . & - & & -............... & - \\
\hline Unknown.. & $\left\{\begin{array}{r}\text { SSSG-1 } \\
-11 \\
-111\end{array}\right.$ & $\begin{array}{l}1 \\
1 \\
1\end{array}$ & $\begin{array}{l}1 \\
2 \\
1\end{array}$ & $\begin{array}{r}\text { SSSL } 1 \text { 1 } \\
-11 \ldots \\
-111\end{array}$ & $\begin{array}{l}5 \\
5 \\
6\end{array}$ & $\begin{array}{l}5 \\
5 \\
9\end{array}$ & & (-2) & - & & - & - \\
\hline & A & 1 & 1.3 & A verage & 5.3 & 6.3 & & & & & $\cdots$ & $\cdots$ \\
\hline
\end{tabular}

1 Estimated. The specimen was taken out of test in the previous cycle, but the appearance of the second face indicated that the failure point would probably have been reached in the next cycle.

Specimen was taken out of test before the second face had reached the failure point.

S Specimen was lost before the conclusion of the test. 
TABLE 4.-Results of spray corrosion tests made with sodium chloride and ammonium chloride solutions of normal strength

[The specimens were taken out of test at irregular intervals for inspection and the noting of the progress of corrosion. They were washed and brushed as free of corrosion products as possible before each inspection]

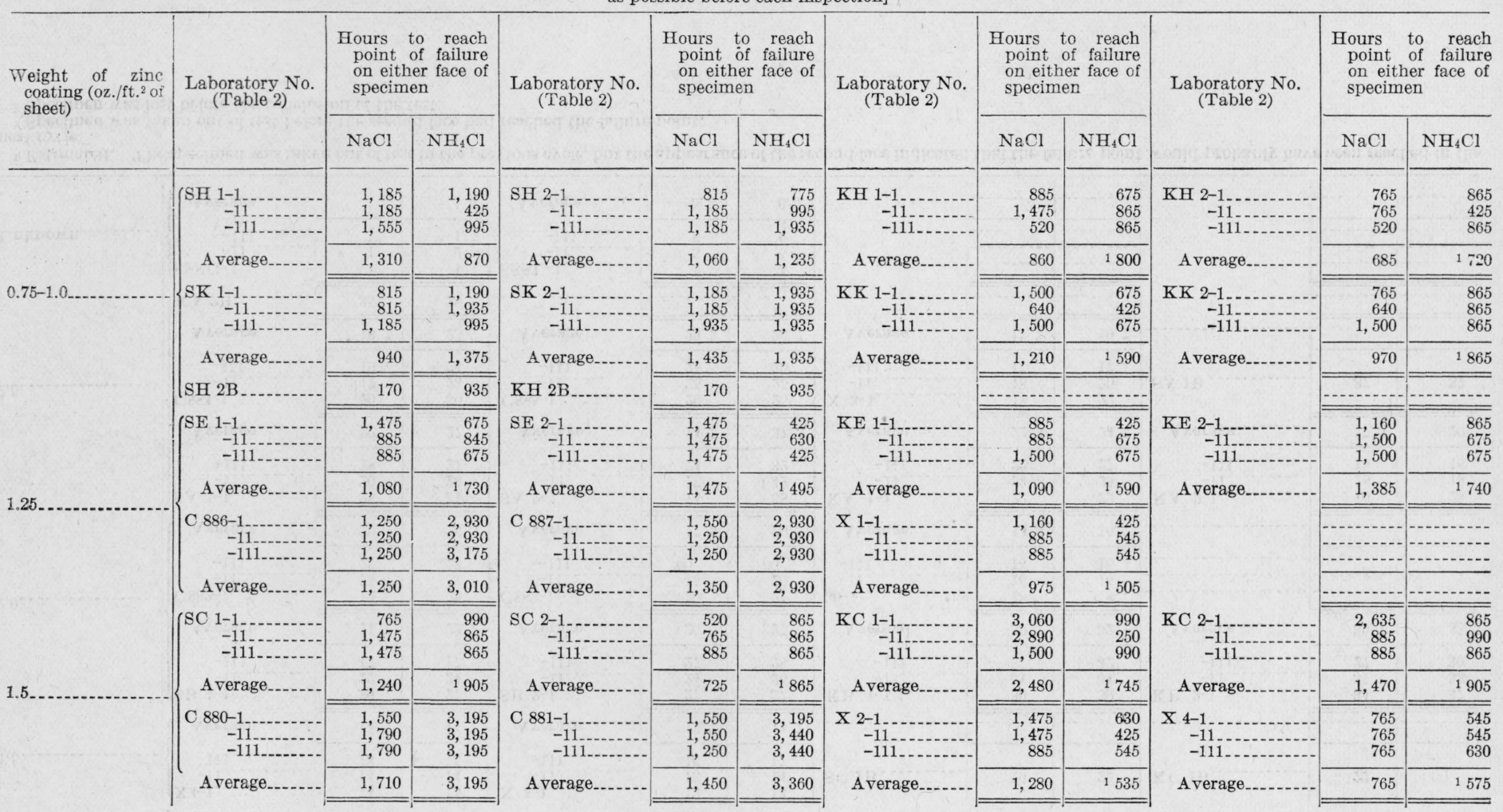




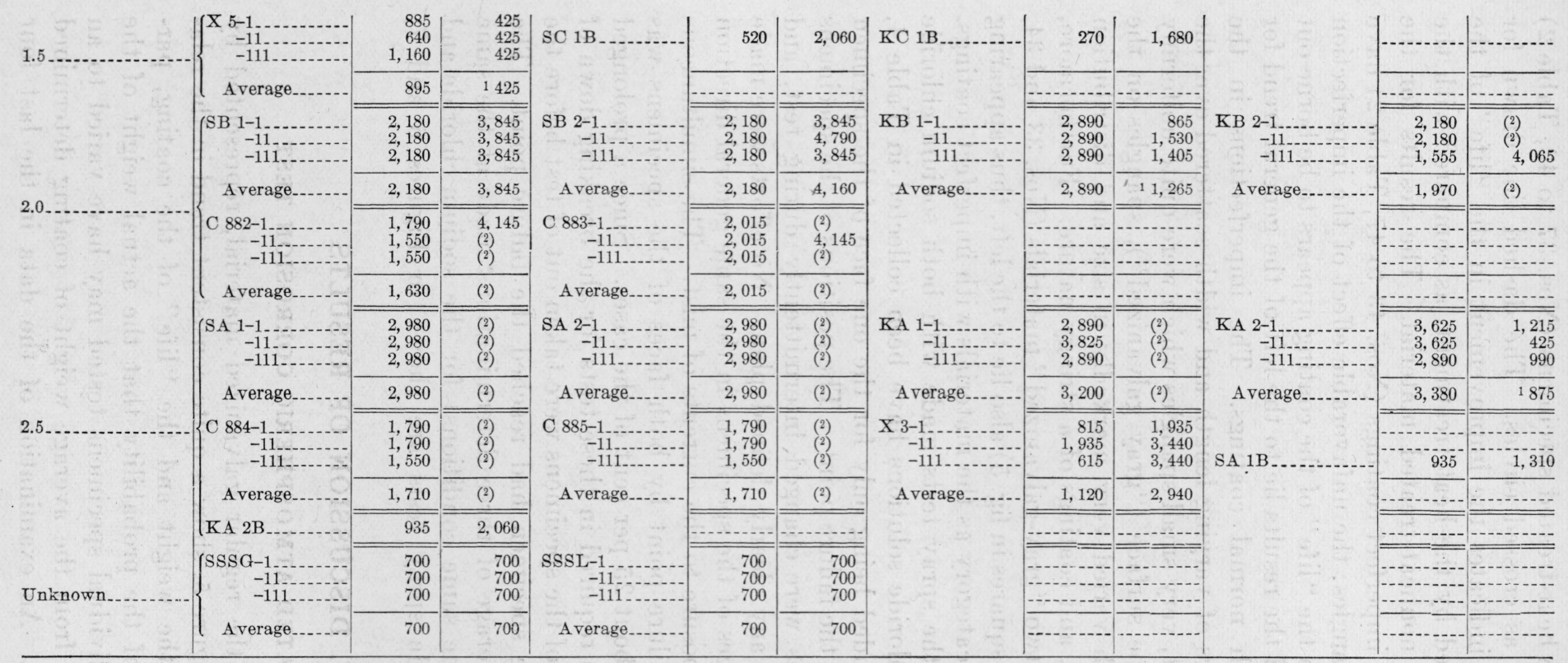

1 These specimens were put into the ammonium chloride spray test and had reached the failure point before the simulated atmospheric corrosion tests were started. The KA specimens were put into test at the same time but did not reach the failure point for a long time afterwards.

2 Over 5,000 hours. 
The data for the heat-treated specimens (Nos. 37 to 42, Table 2) have been plotted as crossed circles. The dashed line drawn for these data clearly indicates the improvement in the "life" of the coating to be gained by the heat treatment, as compared with the solid line for the nonheat-treated material. The results for the test materials with imperfect coatings (Nos. 43 to 47, Table 2) have been plotted as triangles; the unfavorable effect of the imperfection in the coating upon the "life" of the coating appears to be borne out by the fact that all the results lie to the left of the general trend for the materials with normal coatings. The imperfections in the coating were blisters of varying length and width scattered over the surface of the sheet, very small spangles which were quite uniformly distributed over the surface ("gray galvanized"), spangles on the same surface which varied very markedly in size and distribution ("irregular gray"), and coatings of a stringy nature. Furthermore, the results for the two "gray-galvanized" materials (Nos. 33 and 34, Table 2, plotted as squares in fig. 5) also lie to the left, thus appearing to fall in the same category as the materials with imperfect coatings.

The results for the spray tests made with both sodium chloride and ammonium chloride solutions have been collected in Table 4, the data here included being only for the one face of the specimen which first reached the failure point. The positions of the specimens in the spray boxes were changed intermittently during test, and without regard to any clearly defined plan. No efforts were made to maintain the faces of the specimens in the same general direction with respect to exposure to the currents of mist. The simultaneous reaching of the failure point by both faces of the specimens was observed in only about 25 per cent of the cases. Since a prolonged period of time was required in these tests for the breaking down of the coating, many of the specimens were taken out of test before the second face of the specimen had reached the failure point. The plotted results (average of three determinations made at the same time and under the same conditions) for the sodium chloride and ammonium chloride spray tests are shown in Figures 6 and 7 , respectively.

\section{DISCUSSION OF RESULTS}

\section{SIMULATED ATMOSPHERIC CORROSION TEST}

The results for the regular galvanized material, represented by the solid line in Figure 5, show a quite consistent trend in the relationship between the weight and the "life" of the coating, particularly in view of the probability that the actual weight of the coating on the individual specimens tested may have varied to an appreciable extent from the average weight of coating determined for the large sheet. An examination of the data in the last four 
columns in Table 2 will indicate that such a variation occurs, and that the variation tends to be greater with the heavier coats. This is borne out by the greater scattering of the plotted data for the heavier coated materials shown in Figure 5. Furthermore, it has been stated in a handbook on the manufacture of steel products ${ }^{14}$ that a variation of 0.35 ounce per square foot of sheet in a 2-ounce coat is considered as satisfactory in good commercial practice, even when the galvanizing operation is carried out mechanically.

The only known published data for hot-dip galvanized sheets tested by this form of testing method are those reported by Finkeldey in connection with some accelerated tests that were carried out by the American Society for Testing Materials through Subcommittee VII of its Committee $\mathrm{A}-5 .^{15}$ Since in these tests the exposure of the specimens to the corroding atmosphere and to the water spray during each 24-hour cycle was twice as long as in our tests, direct comparisons in the results of both tests could hardly be expected. One should rather look for a shorter "life" on the part of the coating exposed for a longer time per cycle to the corroding influences. In the three cases reported, the specimens, which had a coating of 4.36 and 5.20 ounces per squre foot of sheet (2.18 and 2.60 ounces per square foot of surface) showed a "life" of about 25 to 30 cycles. The extrapolation of the solid line in Figure 5 would indicate a "life" for a 5.0-ounce coating of about 50 cycles, which is about twice the number of cycles required under the above-mentioned more concentrated conditions. It might appear from this that approximately the same ratio holds between the length of exposure to the corroding conditions and the number of cycles required for the coating to reach the failure point; further data would be needed to establish this conclusion.

The results for the six specimens of regular galvanized materials, which were subjected to an annealing treatment for one-half hour at $500^{\circ} \mathrm{C}$. for the purpose of converting, through diffusion, at least a considerable portion of the zinc coating into an iron-zinc alloy, were also quite consistent (crossed circles and dashed line in fig. 5). The employment of a relatively high temperature should increase the affinity between the iron of the base metal and the zinc in the coating and consequently the amount of the iron-zinc alloy formed. ${ }^{16}$ This heat treatment appears to have prolonged somewhat the "life" of the coating, especially in the case of specimens with heavier zinc coatings. A possible explanation for this seems to be that, since the

\footnotetext{
14 Camp and Francis, The Making, Shaping, and Treating of Steel, 4th ed., p. 970; 1925.

15 See p. 145 of reference cited in footnote 6.

16 The heat treatment of hot-dipped zinc coatings has been discussed by H. S. Rawdon in his book, Protective Metallic Coatings, American Chemical Society Monograph Series No. 40, Chemical Catalog Co. (Inc.); p. 97; 1928. Also see Figure 27 on p. 92, which gives a much clearer reproduction of the micrographs shown in Figures 7 to 10 of W. H. Finkeldey's paper, "Microstructure of zinc coatings," Proc. Am. Soc. Test. Mat., 26, Pt. II, p. 308; 1926.
} 
amount of zinc metal in the outer portions of the coating was evidently reduced, the corrosive attack produced by the corrodent in question on the iron-zinc alloy as a whole proceeded at a slower rate than would have been the case if portions of an overlying zinc metal layer were present whereby the general corrosive attack would have been accelerated by the reaction between the anodic zinc layer and the cathodic iron-zinc alloy layer. This accelerative effect should be the more marked as the weight of the zinc coating increases and the coating tends to become more uneven in thickness. The corroding away of the zinc metal layer down to the underlying iron-zinc alloy layer should occur at a considerably earlier stage along the relatively much thinner portions, as at the boundaries of the spangles and between the fernlike ribs of the rosette-shaped spangles, than elsewhere.

With the materials having a lower grade of coating, such as graygalvanized, blistered coatings, etc. (see Nos. 33, 34, and 43 to 47 , inclusive, Table 2), the results, which have been plotted in Figure 5 as triangles and squares, show a decided trend toward a shorter "life." The less satisfactory nature of the coating appears to be thus confirmed.

A record was kept of the progressive changes in the surface appearance of the coating for the various specimens in the course of test. The general type of progressive changes was found to be much the same as that outlined by Finkeldey. (See Sec. II, p. 258.) Figures $9,10,11,13$, and 15 show several characteristic types of the progressive corroding away of the zinc coating, and Figures 8, 12, 14 , and 16, for purposes of comparison, the original appearance of the materials having the lightest and heaviest hot-dip galvanized coatings, "gray-galvanized" coating, and lead coating. In all cases, the hot-dip galvanized specimens began to lose their metallic luster in the first cycle. Dark-colored (dark gray or blue black) patches began to appear at the thinnest portions of the coating after, on an average, about 2 or 3 cycles for the lightest coatings ( 0.75 to 1.25 ounces) and about 10 cycles for the heaviest coatings (2.5 ounces). These patches generally started along the boundaries of the grains or spangles (figs. 17, 18, and 19) and extended out in an irregular manner. These dark-colored areas ( $B$ in figs. 9, 10, 11 , and 13) were the portions of the outer iron-zinc alloy (presumably $\mathrm{FeZn}_{7}$ ) which had been laid bare by the removal of the overlying layer of zinc metal. Next, after an additional number of cycles, there appeared in one or more places in the dark-colored patches light areas with a metallic luster $(C)$, which were portions of the subjacent iron-zine layer (probably $\mathrm{FeZn}_{3}$ ). Shortly before and coincident with their appearance there was present on the surface of the specimen, in conjunction with their locations, a yellow-colored film 
B. S. Journal of Research, RP10

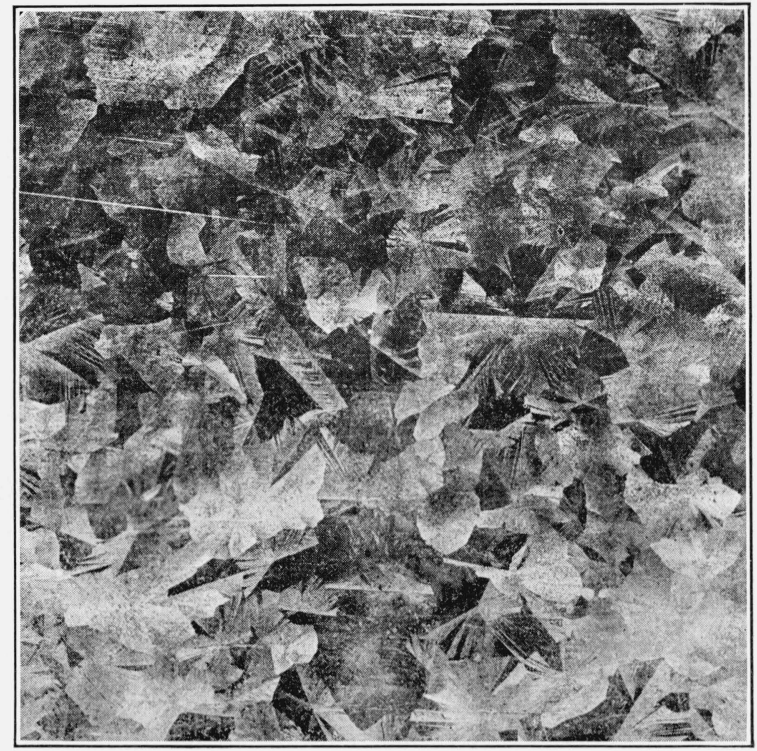

FIG. 8.-Appearance of an 0.9-ounce coating in the "as received" condition. (Material No. 4, Table 2.) $\times 3 / 4$

This coat had a smooth surface with no ridges between the adjacent spangles standing out in relief

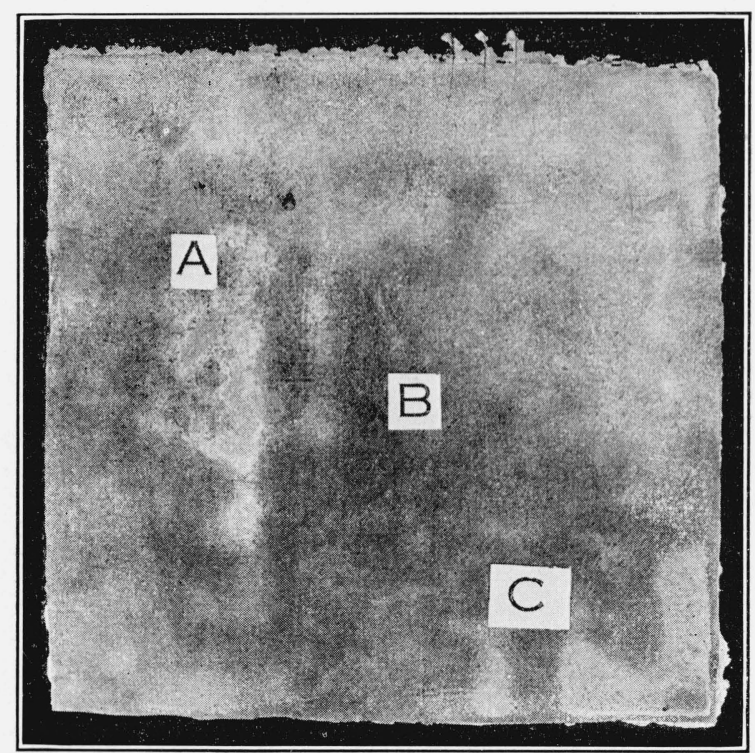

FIG. 9.-Change in appearance of an 0.8-ounce coating after 11 cycles' exposure in the simulated atmospheric corrosion test. (Material No. 21, specimen SK1-111, Table 2.) $\times 3 / 4$

$A$, relies of zinc metal layer; $B$, outer iron-zinc alloy layer; $C$, inner jiron-zinc alloy layer; the dark patch shown in the lower right corner of the L-shaped area is red-brown iron rust 
B. S. Journal of Research, RP10

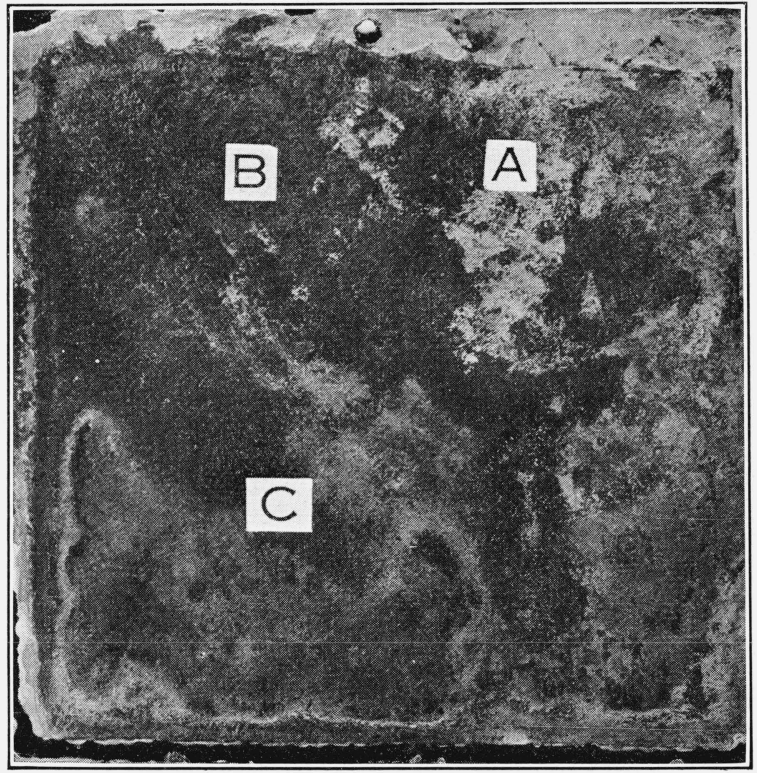

FIG. 10.-Change in appearance of a 2.2-ounce coating after 34 cycles' exposure in the simulated atmospheric corrosion test. (Material No. 15, specimen KB1-11, Table 2.) $\times 3 / 4$

$A$, relics of zinc metal layer; $B$, outer iron-zinc alloy layer; $C$, inner iron-zinc alloy layer; the dark patches shown scattered through this area are red-brown iron rust

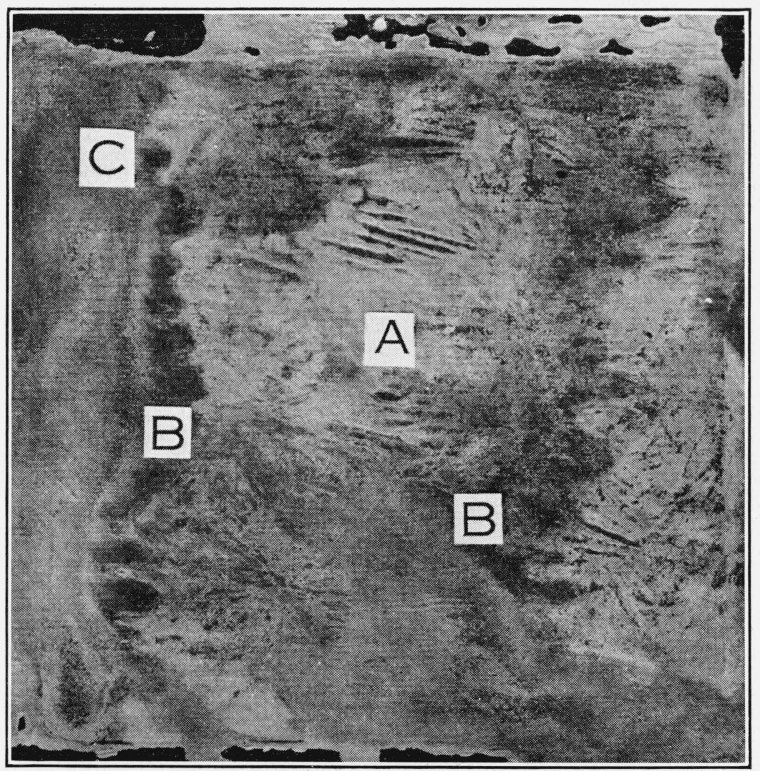

FIG. 11.-Change in appearance of a 2.1-ounce coating after 23 cycles' exposure in the simulated atmospheric corrosion test. (Material No. 30, specimen 883-11, Table 2.) $\times 3 / 4$

$A$, relics of zinc metal layer; $B$, outer iron-zinc alloy layer; $C$, inner iron-zinc alloy layer; the dark patch shown at the lower end of this elongated area is red-brown iron rust 


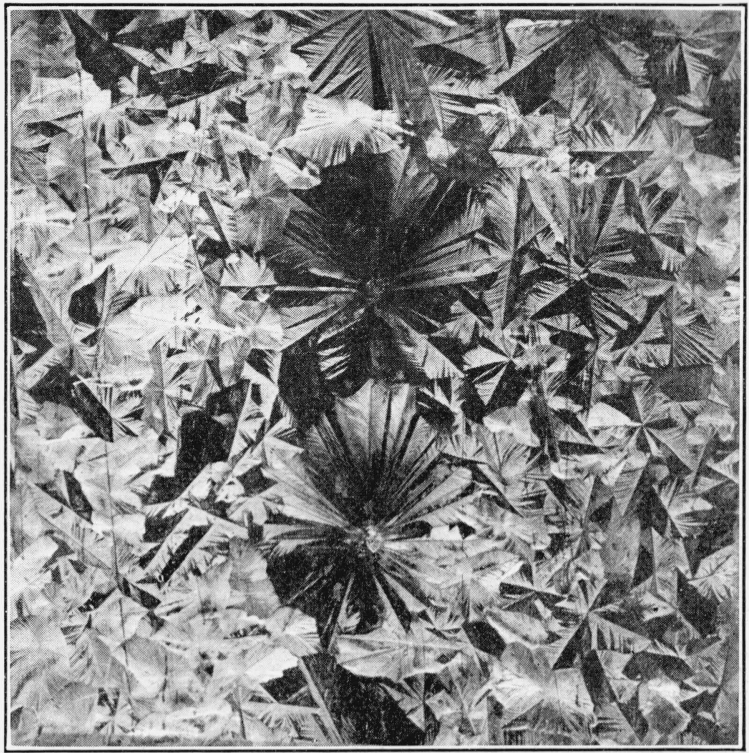

FIG. 12.-A ppearance of a 2.6-ounce coating in the "as received" condition. (Material No. 18, Table 2.) $\times 3 / 4$

Various portions of the surface, as along the boundaries between the spangles and also alongside some of the dendritic branches of the spangle, stood out in decided relief and the corroding through of the zinc metal layer usually occurred first at these places where the coating was thinnest. In the center of the two large adjacent spangles may be seen "chain conveyor marks." Several materials having these marks, which were generally not deep-seated, showed no tendency for the failure point to occur first at these points

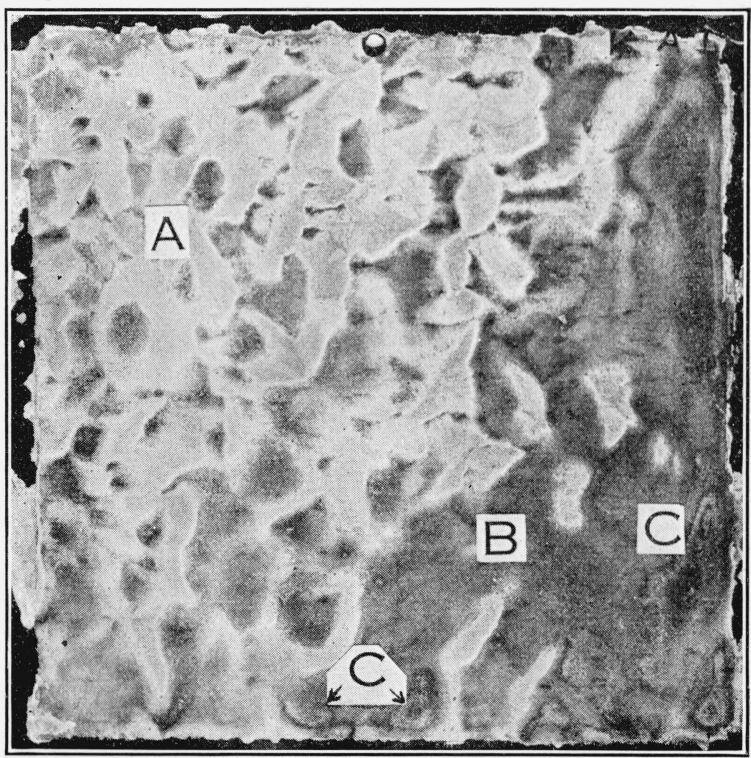

FIG. 13.-Change in appearance of a 2.7-ounce coating after 27 cycles' exposure in the simulated atmospheric corrosion test. (Material No. 19, specimen KA1-11, Table 2.) $\times 3 / 4$

$A$, relics of the zinc metal layer; $B$, outer iron-zinc alloy layer; $C$, inner iron-zinc alloy layer; the darker portions of these areas are red-brown iron rust 
B. S. Journal of Research, RP10

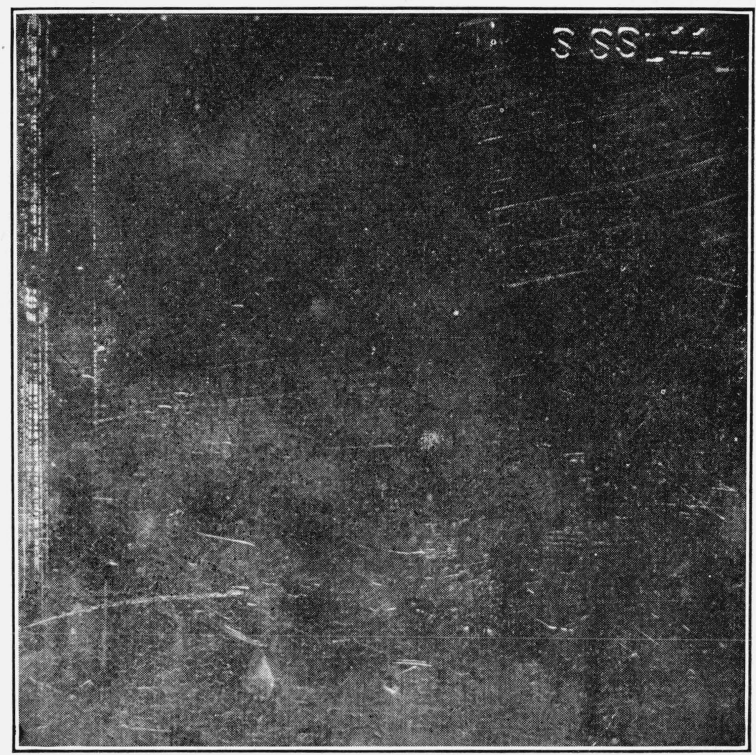

FIG. 14.-Appearance of a specimen of lead-coated material in the "as received" condition. (Material No. 35, Table 2.) × $3 / 4$

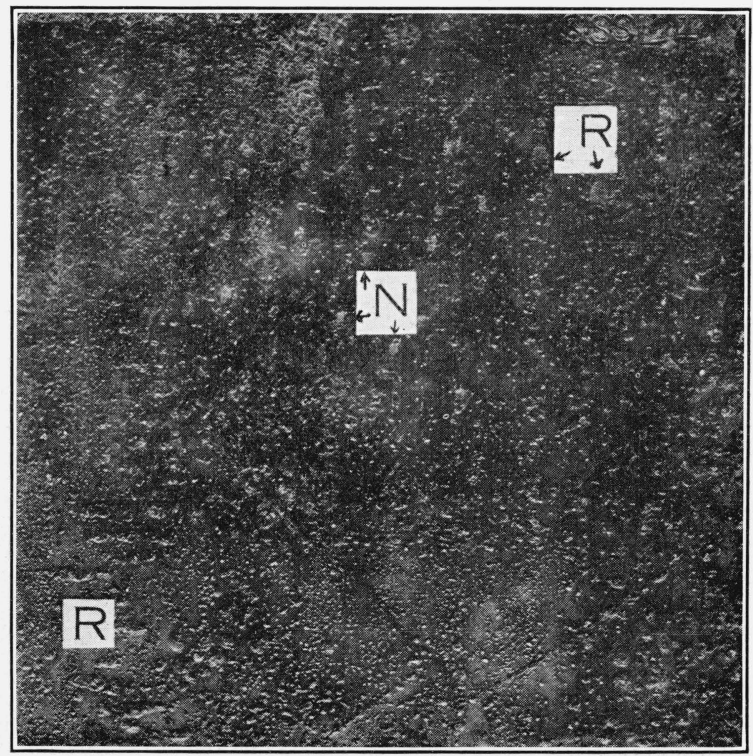

FIG. 15.-Change in appearance of a specimen of lead-coated material after 55 cycles' exposure in the simulated atmospheric corrosion test. (Material No. 35, specimen SSSL-1, Table 2.) $\times 3 / 4$

The lead coat is badly roughened and many blisters have formed (compare with fig. 14). The underlying surface at some of the blisters is 'strongly rusted $(R)$ while that at some of the other blisters show a gray-colored, matte appearance $(N)$. This specimen had reached the "failure point" after 5 cycles, exposure 


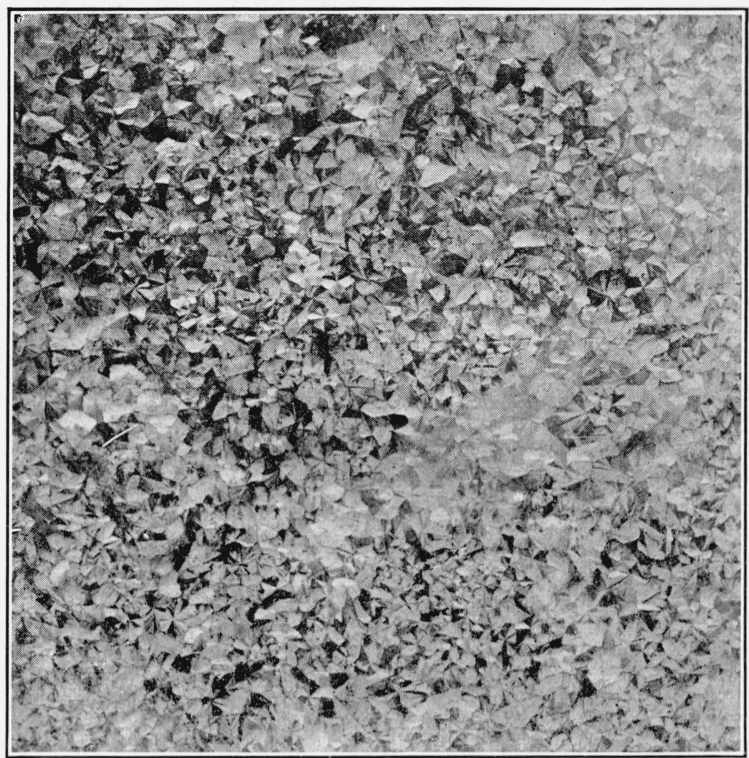

FIG. 16.-A ppearance of a "gray galvanized" coating in the "as received" condition (1.6-ounce coating; material No. 46, Table 2.) $\quad \times 3 / 4$

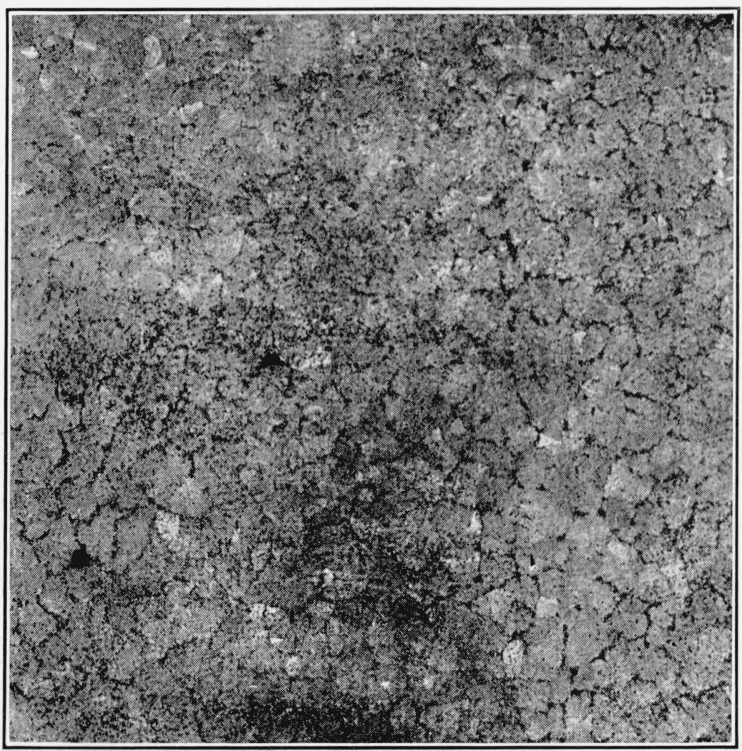

FIG. 17.-Change in appearance of the "gray galvanized" coating after 5 cycles' exposure in the simulated atmospheric corrosion test (1.6-ounce coating; material No. 46, specimen X5-1, Table 2.) $\times 1$

The corroding away of the "gray galvanized" coat has started along the grain boundaries 
B. S. Journal of Research, RP10

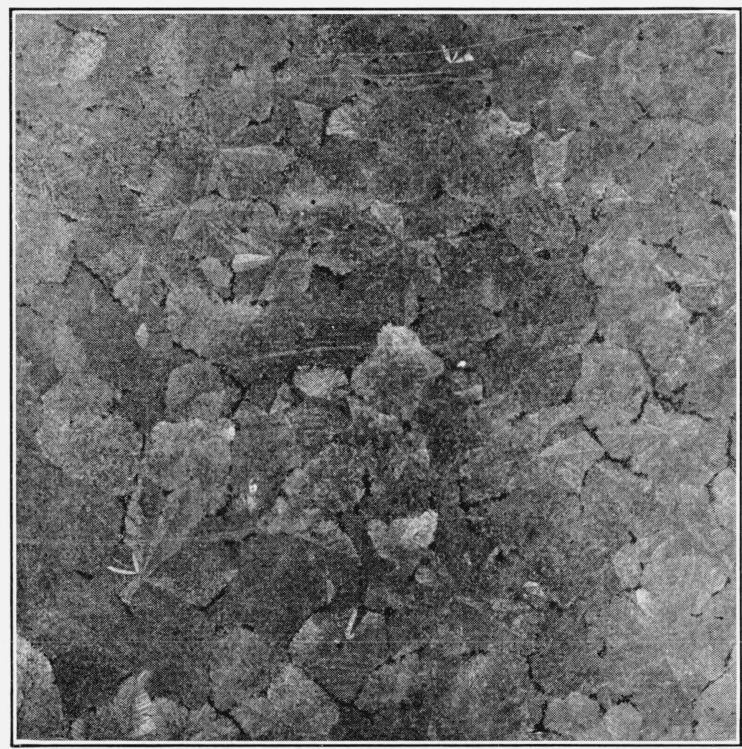

FIG. 18.-Change in appearance of a 1.7-ounce coating after 5 cycles' exposure in the simulated atmospheric corrosion test (Material No. 45, specimen $\mathrm{X}_{4}-1$, Table 2.) $\times 1$

The corroding away of the coating has started along the grain boundaries

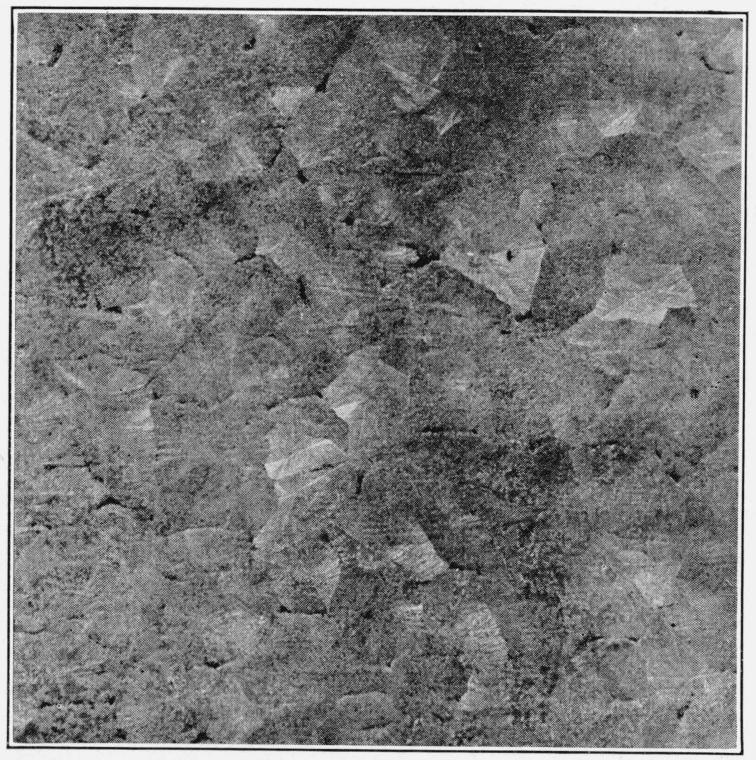

FIG. 19.-Change in appearance of a 2.7-ounce coating after 5 cycles' exposure in the simulated atmospheric corrosion test. (Material No. 19, specimen KA1-11, Table 2.) $\times 1$

The corroding away of the coating is starting at the junctions between the adjoining grains 
(a corrosion product containing both zine and iron) which was easily brushed off during the cleaning operation following the water-spraying stage of the cycle. In the following cycles this inner iron-zinc alloy layer gave way, usually along the central portions of the exposed surface, to the underlying base metal, whose presence was made evident by the formation, at these points, of red-brown iron rust. The first definite appearance of this rust constituted the

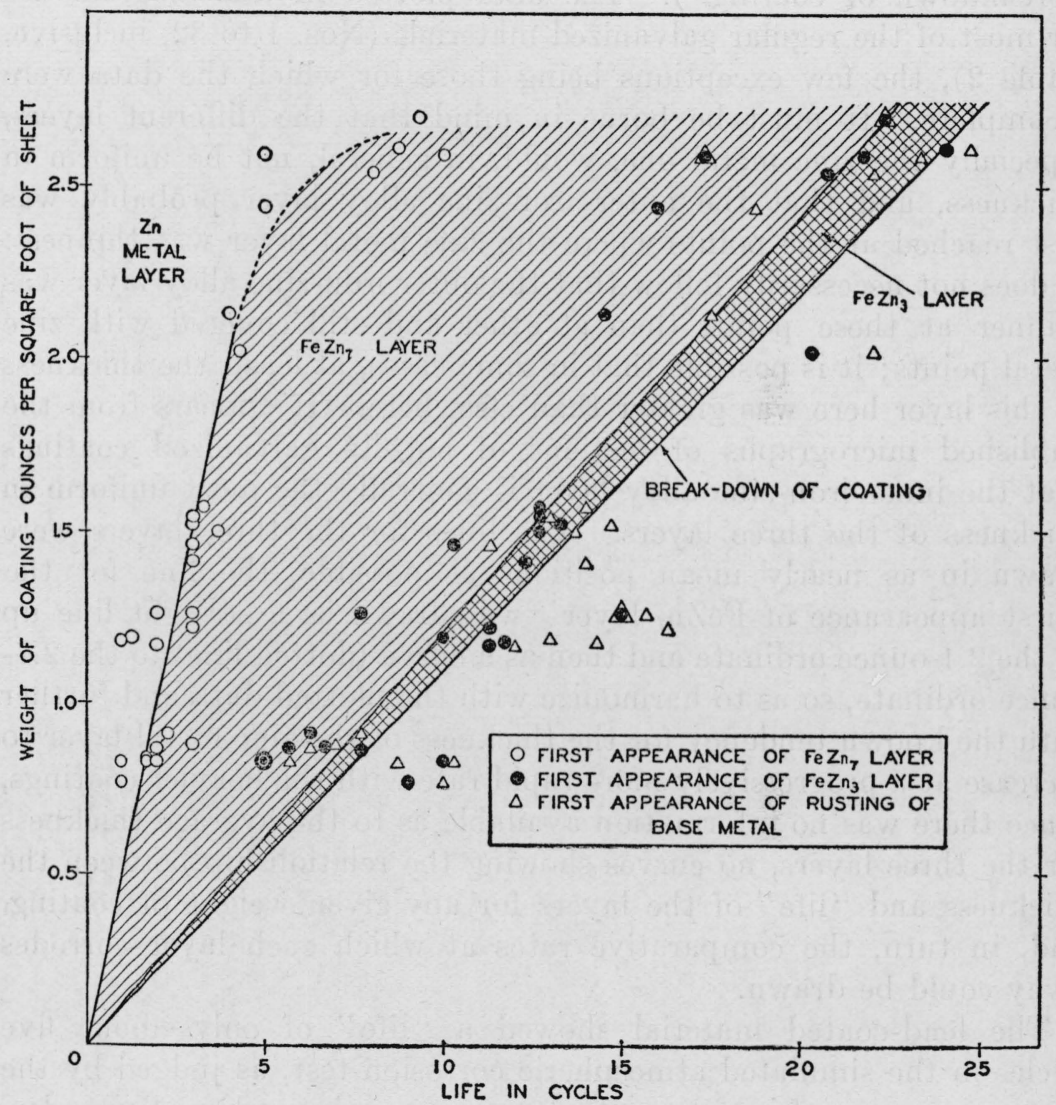

Fig. 20.- "Life" of the three layers constituting hot-dip zinc coatings, as determined by the first appearance of the inner two layers and base metal in the simulated atmospheric corrosion test

Each point plotted in this diagram is the average of three determinations

"failure-point" in these tests. The rusted areas are clearly indicated in Figures 9, 10, 11, and 13, as dark patches lying within the lighter areas designated by $C$. With the heavier-coated materials, there was, oftentimes, a considerable portion of the zinc-metal layer, $A$, which remained quite intact while the corrosion of the other portion of the surface had proceeded to the outer and inner iron-zinc alloy layers and to the base metal. (See fig. 13.) There were also cases 
noted, as illustrated by Figure 11, where the zinc coating at different portions of the surface was distinctly irregular in thickness.

Figure 20 shows the "life" of the three components of the zinc coating, as judged by the time from the start of the tests, expressed in cycles, required for the first appearance of the outer iron-zinc alloy $\left(\mathrm{FeZn}_{7}\right)$, the inner iron-zine alloy $\left(\mathrm{FeZn}_{3}\right)$, and the red-brown iron rust due to the corroding of the base metal (designated as the "breakdown of coating"). The data plotted in this diagram are for most of the regular galvanized materials (Nos. 1 to 32, inclusive, Table 2), the few exceptions being those for which the data were incomplete. It must be borne in mind that the different layers, especially the zinc metal one, would, in general, not be uniform in thickness, and that the outer iron-zinc alloy layer probably was first reached at the points where the zine metal layer was thinnest. It does not necessarily follow that the outer iron-zinc alloy layer was thinner at these points than at other and still covered with zinc metal points; it is possible that in some cases, at least, the thickness of this layer here was greater than elsewhere. It appears from the published micrographs of sections of hot-dip galvanized coatings that the inner iron-zinc alloy layer is generally the most uniform in thickness of the three layers. The lines for the three layers were drawn in as nearly mean positions as possible; the line for the "first appearance of $\mathrm{FeZn}$ layer" was drawn as a straight line up to the 2.1-ounce ordinate and then as a curve (dotted line) to the 2.7ounce ordinate, so as to harmonize with the plotted data and further with the known tendency for the thickness of the zinc metal layer to increase at a progressively more rapid rate with the heavier coatings, Since there was no information available as to the average thickness for the three layers, no curves showing the relationship between the thickness and "life" of the layers for any given weight of coating. and, in turn, the comparative rates at which each layer corrodes away could be drawn.

The lead-coated material showed a "life" of only about five cycles in the simulated atmospheric corrosion test, as judged by the first appearance of iron rust at one or more points where the underlying metal had been laid bare by comparatively very small-sized blisters that had formed in the lead coating. The "breaking down" of the lead coating started with the formation, in the second or third cycle, of blisters in the coating, followed first by the appearance in or around the blisters of a yellow-colored rust ascribed to the corroding of the iron-zinc alloy in a thin zinc coating which must have been present between the lead coating and the steel base, and finally by the presence within the blistered area of red-brown rust produced by the corroding of the steel base. The lead coating itself remained uncorroded, yet the very fact that, under the conditions of the test, 
B. S. Journal of Research, RP10

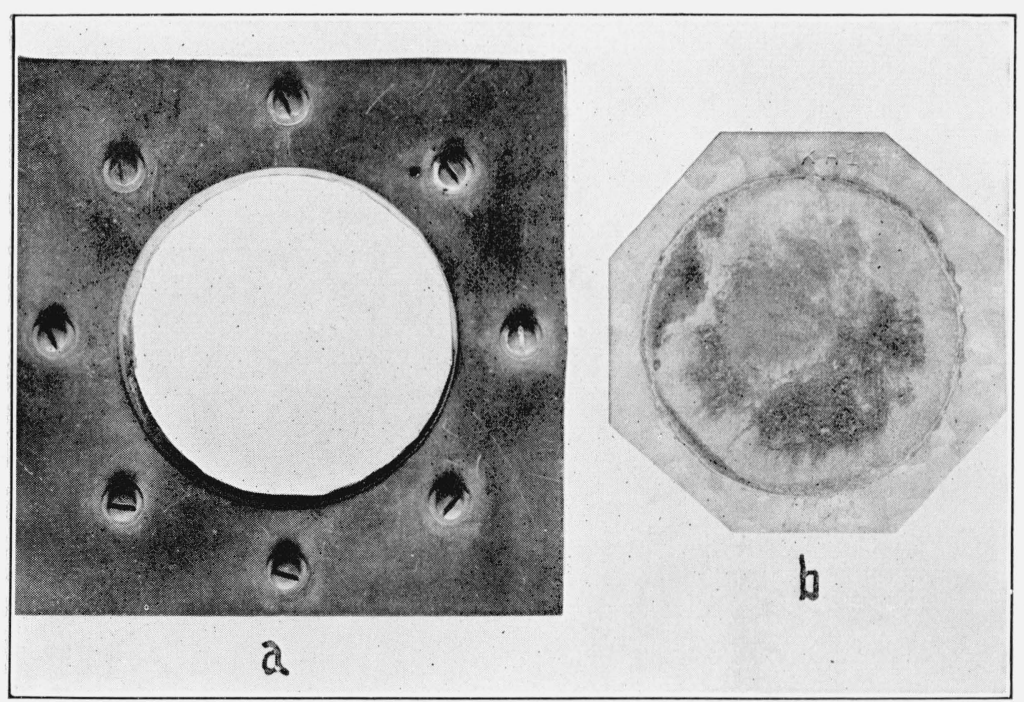

FIG. 21.-Clamping arrangement used for exposing a definite area of the specimen in the tests made to determine the rate of loss in weight of the zinc coating. $\times 1 / 2$

$a$, clamping arrangement; $b$, specimen; the dark areas shown inside of the circular area on the face of the specimen are red-brown iron rust 
it showed a tendency to blister lessened its value as a protective coating, at least in the case of thin coatings. The formation of blisters, simultaneous with that of very small moundlike protuberances in the intervening portions of the lead coating, increased in extent with the time of exposure. After a sufficiently long exposure the lead coating assumed a generally roughened and unsightly appearance, with small rusted areas scattered here and there. Figure 15 shows the appearance, after 55 cycles exposure, of one of the three specimens which were kept in test for many additional cycles after the "failure point" had been reached with the object of observing the progressive development of the roughened surface. Here the lead coating appears badly roughened (compare with fig. 14) and with blisters formed in many places. The underlying metal left bare by some of these blisters was strongly rusted, while that at other places showed a gray, mattelike appearance quite free from rust. The behavior manifested during this long exposure confirmed the conclusion that the lead-coated material had been galvanized before the lead coating was applied, and that the latter shows a distinct tendency to separate from the underlying zinc coating as corrosion progresses. Furthermore, it is apparent that the simulated atmospheric corrosion test serves admirably to show the presence of "pinholes" in lead coatings.

It was of interest to know whether or not the corroding away of the zinc coating was maintained at any definite rate for all the cycles up to the point of failure, and this rate was independent of the initial weight of coating. Some tests were carried out in an attempt to determine this point experimentally. Specimens of selected materials were mounted in hard-rubber clamps provided with a circular hole having an area of 3 square inches $\left(1,935 \mathrm{~mm}^{2}\right)$. Figure 21 shows one of these clamps and also one of the specimens used in these tests. The specimen was clamped between two sheets of soft rubber, each being about one-sixteenth inch $(2 \mathrm{~mm})$ thick and having the same size hole as that in the mount, inside of the mount. Care was taken with the aid of reference marks to place the specimen back in the same position, with respect to the edge of the hole, for each succeeding cycle in order that the area on both surfaces of the specimen exposed in the series of cycles remained always the same during test. The clamps with the specimens mounted therein were placed in a vertical position on the specimen holder in the test apparatus ( $S H$, fig. 2(a)). There were included with the series of coated specimens two specimens of commercially pure sheet zinc, 4 inches $(102 \mathrm{~mm})$ square and 0.017 inch $(0.4 \mathrm{~mm})$ thick. A typical analysis of this zine material was as follows: $\mathrm{Pb}, 0.19$ per cent; $\mathrm{Cd}, 0.38$ per cent; $\mathrm{Fe}, 0.02$ per cent; $\mathrm{Cu}$, not detected; and $\mathrm{Zn}, 99.41$ per cent (by difference). The results of two series of tests, the second one being carried out as a matter of checking up the first one, are given in Table 5. The losses in weight 
for the individual zinc-coated and zinc-metal specimens were found to vary in an irregular manner from cycle to cycle between the limits given in the sixth and seventh columns of Table 5. The variations lay within the range, 0.013 to $0.033 \mathrm{oz} . / \mathrm{ft}^{2}{ }^{2}$ of sheet in 93 per cent of the cases for the first series and 0.018 to $0.055 \mathrm{oz} . / \mathrm{ft} .^{2}$ of sheet in 91 per cent of the cases for the second series. However, in both series of tests, the average loss in weight per cycle (fifth column, Table 5) for the zinc-coated specimens approached a quite definite value, which was independent of the initial weight of coating. These average values were in good agreement with those for the zinc metal specimens. Furthermore, the ratio of the initial weight of coating to the total loss in weight (last column, Table 5) approached a constant value, which was independent of the initial weight of coating. In comparing the results of the first series with those of the second series, these average values differ rather markedly. The only explanation offered to account for the greater losses in weight in the second series is that the concentration of the corroding gases may possibly have been allowed to run at a little higher level than in the first series. It is of interest to note that the loss in weight suffered by most of the coated specimens in both series was greater in the first cycle than in the subsequent cycles.

TABLE 5.-Results of tests made to show the rate at which the zinc coating lost in weight in the simulated atmospheric corrosion test

FIRST SERIES

\begin{tabular}{|c|c|c|c|c|c|c|c|c|c|}
\hline \multirow{3}{*}{$\begin{array}{l}\text { Laboratory No. } \\
\text { (Table 2) }\end{array}$} & \multirow{3}{*}{$\begin{array}{c}\text { Weight } \\
\text { of zinc } \\
\text { coating } \\
(W) \text {, as } \\
\text { deter- } \\
\text { mined } \\
\text { by } \\
\text { weighing } \\
\text { method }\end{array}$} & \multicolumn{7}{|c|}{ Tested to point of failure } & \multirow{3}{*}{$\begin{array}{l}\text { Ratio } \\
\text { weight } \\
\text { of } \\
\text { coating } \\
\text { to total } \\
\text { loss in } \\
\text { weight }\end{array}$} \\
\hline & & \multirow{2}{*}{$\begin{array}{l}\text { Num- } \\
\text { ber of } \\
\text { cycles }\end{array}$} & \multirow{2}{*}{$\begin{array}{c}\text { Total } \\
\text { loss in } \\
\text { weight of } \\
\text { specimen } \\
(T L)\end{array}$} & \multirow{2}{*}{$\begin{array}{c}\text { A verage } \\
\text { loss in } \\
\text { weight of } \\
\text { specimen } \\
\text { per cycle }\end{array}$} & \multicolumn{2}{|c|}{$\begin{array}{l}\text { Loss in weight } \\
\text { in any cycle }\end{array}$} & \multicolumn{2}{|c|}{$\begin{array}{l}\text { Deviation } \\
\text { from average } \\
\text { loss in weight }\end{array}$} & \\
\hline & & & & & $\begin{array}{l}\text { Maxi- } \\
\text { mum }\end{array}$ & $\begin{array}{l}\text { Mini- } \\
\text { mum }\end{array}$ & $\begin{array}{l}\text { Maxi- } \\
\text { mum }\end{array}$ & $\begin{array}{l}\text { Mini- } \\
\text { mum }\end{array}$ & \\
\hline $\begin{array}{l}\text { SH } 1 \\
\text { KH } 1 \\
\text { KE } 1 \\
\text { KC } 1 \\
\text { KB } 1 \\
\text { KA } 1\end{array}$ & $\begin{array}{r}\text { Oz./ft. } \\
\text { of sheet } \\
0.83 \\
.91 \\
1.19 \\
1.50 \\
2.15 \\
2.70 \\
\end{array}$ & $\begin{array}{r}5 \\
5 \\
8 \\
10 \\
13 \\
16 \\
\end{array}$ & $\begin{array}{c}\text { Oz./ft. }{ }^{2} \\
\text { of sheet } \\
0.1029 \\
.1049 \\
.1507 \\
.2081 \\
.2968 \\
.3242 \\
\end{array}$ & $\begin{array}{c}\text { Oz./ft. }{ }^{2} \\
\text { of sheet } \\
0.0206 \\
.0210 \\
.0188 \\
.0208 \\
.0228 \\
.0203\end{array}$ & $\begin{array}{r}\text { Oz./ft. }{ }^{2} \\
\text { of sheet } \\
10.0308 \\
1.0300 \\
1.0308 \\
1.0282 \\
2.0476 \\
2.0346 \\
\end{array}$ & $\begin{array}{r}\text { Oz./ft. }{ }^{2} \\
\text { of sheet } \\
0.0155 \\
.0137 \\
.0135 \\
.0148 \\
.0140 \\
.0104 \\
\end{array}$ & \begin{tabular}{|r} 
Per cent \\
49.5 \\
42.9 \\
63.8 \\
35.6 \\
108.8 \\
70.4 \\
\end{tabular} & \begin{tabular}{|c} 
Per cent \\
24.8 \\
34.8 \\
28.2 \\
28.8 \\
38.6 \\
48.8 \\
\end{tabular} & $\begin{array}{r}W / T L \\
8.0 \\
8.7 \\
7.9 \\
7.2 \\
7.2 \\
8.3 \\
\end{array}$ \\
\hline Average. & - nenton & - nne- & $-1-1$ & .0207 & $-\ldots \ldots$. & - & ...... & . & 7.9 \\
\hline $\begin{array}{l}\text { Zine No. } 1 \\
\text { Zine No. } 2 . .\end{array}$ & (1) & $\begin{array}{l}16 \\
16\end{array}$ & $\begin{array}{l}.3421 \\
.3646\end{array}$ & $\begin{array}{l}.0214 \\
.0228\end{array}$ & $\begin{array}{l}3.0310 \\
3.0386\end{array}$ & .0112 & $\begin{array}{l}44.9 \\
69.3\end{array}$ & $\begin{array}{l}47.7 \\
40.8\end{array}$ & \\
\hline
\end{tabular}

SECOND SERIES

\begin{tabular}{|c|c|c|c|c|c|c|c|c|c|}
\hline $\begin{array}{l}\text { SH } 1 \\
\text { KH } 11 \\
\text { KE } 11 \\
\text { KC } 11 \\
\text { KB } 11 \ldots \\
\text { KA } 11\end{array}$ & $\begin{array}{l}0.83 \\
.91 \\
1.19 \\
1.50 \\
2.15 \\
2.70\end{array}$ & $\begin{array}{r}4 \\
5 \\
7 \\
7 \\
12 \\
17\end{array}$ & $\begin{array}{r}0.1199 \\
.1404 \\
.1967 \\
.2016 \\
.3655 \\
.5053 \\
\end{array}$ & $\begin{array}{r}0.0300 \\
.0281 \\
.0281 \\
.0288 \\
.0305 \\
.0297 \\
\end{array}$ & $\begin{array}{r}10.0581 \\
1.0546 \\
1.0557 \\
1.0528 \\
1.0570 \\
1.0478 \\
\end{array}$ & $\begin{array}{r}0.0165 \\
.0163 \\
.0070 \\
.0186 \\
.0180 \\
.0165 \\
\end{array}$ & $\begin{array}{l}93.7 \\
94.3 \\
98.2 \\
83.3 \\
86.9 \\
60.9 \\
\end{array}$ & $\begin{array}{l}45.0 \\
42.0 \\
75.1 \\
35.4 \\
41.0 \\
44.4\end{array}$ & $\begin{array}{l}6.9 \\
6.5 \\
6.0 \\
7.4 \\
5.9 \\
5.3\end{array}$ \\
\hline in & $-\ldots$ & & $\ldots$ & .0292 & 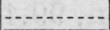 & $\ldots$ & $\ldots$ & $\ldots$ & 6. 3 \\
\hline $\begin{array}{l}\text { Zine No. } 1 \\
\text { Zinc No. } 2\end{array}$ & & $\begin{array}{l}17 \\
17\end{array}$ & $\begin{array}{l}.4709 \\
.4595\end{array}$ & $\begin{array}{l}.0277 \\
.0270\end{array}$ & $\begin{array}{r}1.0397 \\
.0354\end{array}$ & $\begin{array}{l}.0164 \\
.0181\end{array}$ & $\begin{array}{l}43.3 \\
31.1\end{array}$ & $\begin{array}{l}40.8 \\
33.0\end{array}$ & \\
\hline
\end{tabular}

1 In first cycle. For zinc No. 2 in the second series, the maximum loss in the first cycle was not much less (0.0328) than the value given.

2 In twelfth cycle.

${ }_{3}^{3}$ In seventh cycle. 
In order to note what effect, if any, the presence of copper in the steel base of hot-dip galvanized sheets would have on the nature of the iron rust formed by prolonged exposure to the conditions of the simulated atmospheric corrosion test, as compared with the known strong adherence of the rust films formed on copper-bearing steel in ordinary atmospheric corrosion, three pairs of copper-bearing and noncopper-bearing steel specimens having zinc coatings of 0.8 to 0.9 , 1.5, and 2.5 ounces. (Nos. 1, 3, 9, 11, 17, and 19, Table 2) were kept in test for 71 cycles. These specimens were not brushed or cleaned in any manner between cycles and, in fact, were left entirely undisturbed throughout the course of test. The zinc coating had disappeared more or less completely long before the completion of the test. The coat of iron rust thus formed on both the copper-bearing and noncopper-bearing steel specimens appeared to be very similar in nature; that is, it was loosely adherent and similar in texture and color. A typical appearance of the rust coat thus formed on these two classes of sheet material is shown in Figure 22; the rust coat had reached the peeling-off stage when these photographs were taken about eight months after the completion of the test. It is clear that no distinction between the rust coat formed by the two classes of base metal was offered by the conditions of this type of corrosive atmosphere.

\section{SPRAY TESTS}

(a) SODIUM CHLORIDE

The results obtained follow a quite consistent trend, as shown in Figure 6 , and it might appear that this testing method would serve satisfactorily for the determination of the "life" of the galvanized coating. However, a serious drawback is the prolonged time of exposure to the sodium chloride spray required for the specimens to reach the failure point, which is characterized by the formation of red-brown iron rust at the points where the coating has broken down. With a sodium chloride solution of normal strength, approximately 1,000 hours (42 days) for the lightest weight coatings ( 0.75 to 1 ounce) and 3,000 hours (125 days) for the heaviest coatings ( 2.5 ounces) were required to reach the failure point. Another and an important disadvantage is the localized nature of the breakdown of the coating, a further discussion of which will be made in a later paragraph.

It will be noted, in reference to Figure 6 , that, with the exception of the results for the annealed specimens, similar characteristics in the results obtained hold true for this diagram as for the simulated atmospheric corrosion test (fig. 5); that is, there was an appreciable scattering of the plotted data for the regular galvanized materials along the solid line, which was drawn in as nearly a mean position as practicable. Also, the data for the materials with imperfect coatings (plotted as triangles) lay decidedly to the left of the solid line. On the other 
hand, the results for the annealed specimens were on the side of the solid line reverse to that in the simulated atmospheric corrosion test. They showed a much shorter life than the regular, nonannealed galvanized material. A probable reason for this more rapid corrosive action is that a greater electrolytic action is set up by sodium chloride solution with the iron-zinc alloy than with zinc metal. The lead. coated and "galvannealed" specimens (Nos. 35 and 36, Table 2) showed a comparatively short life, namely, 700 hours - a result which approached, approximately, those for the annealed specimens. Since the hot-dip "gray-galvanized" materials (Nos. 33 and 34, Table 2) were received at a time when the spray tests were well along toward completion and the regular hot-dip galvanized material with a similar weight of coating had required a long exposure to reach the failure point, it was considered not worth while to include these materials in the spray tests.

The corroding of the zinc coating occurred in an entirely different manner from that in the simulated atmospheric corrosion test. Here the breakdown of the coating was confined within those portions of the surface of the specimen which had been attacked. There were three distinct types of surface attack: (a) Formation of streaks, extending from the upper to the lower edge of the specimen produced by the downward flow of .condensed spray which had collected along the top edge or at the point where the glass suspension hook entered the hole; $(b)$ a general corroding of the surface that extended over a part or the whole of the face of the specimen and which was produced by a condensation of the spray in the form of small drops distributed over the area in question and somewhat after the manner of dew; and $(c)$ formation of isolated areas at points on the surface where local conditions favored the collection of condensed spray and the consequent corrosion of the underlying coating. The first type was the one met with in most all cases, and the streak extending along the central part from the suspension hole was usually much further developed than the other streaks present on either side of the central streak.

In the light of the experimental results obtained in this work, a different method of supporting the specimens in a vertical position in the spray box, whereby the amount of condensed spray flowing downward from the upper edge could be minimized as much as possible, would have been more desirable than the method of suspending the specimens on glass hooks. Such a method could consist of placing the bottom edge of the specimens within grooves of a bottom support in such a manner that no accumulation of condensed spray would tend to form at the points of contact, which should be well below the upper edge of the enamel border. The specimens 


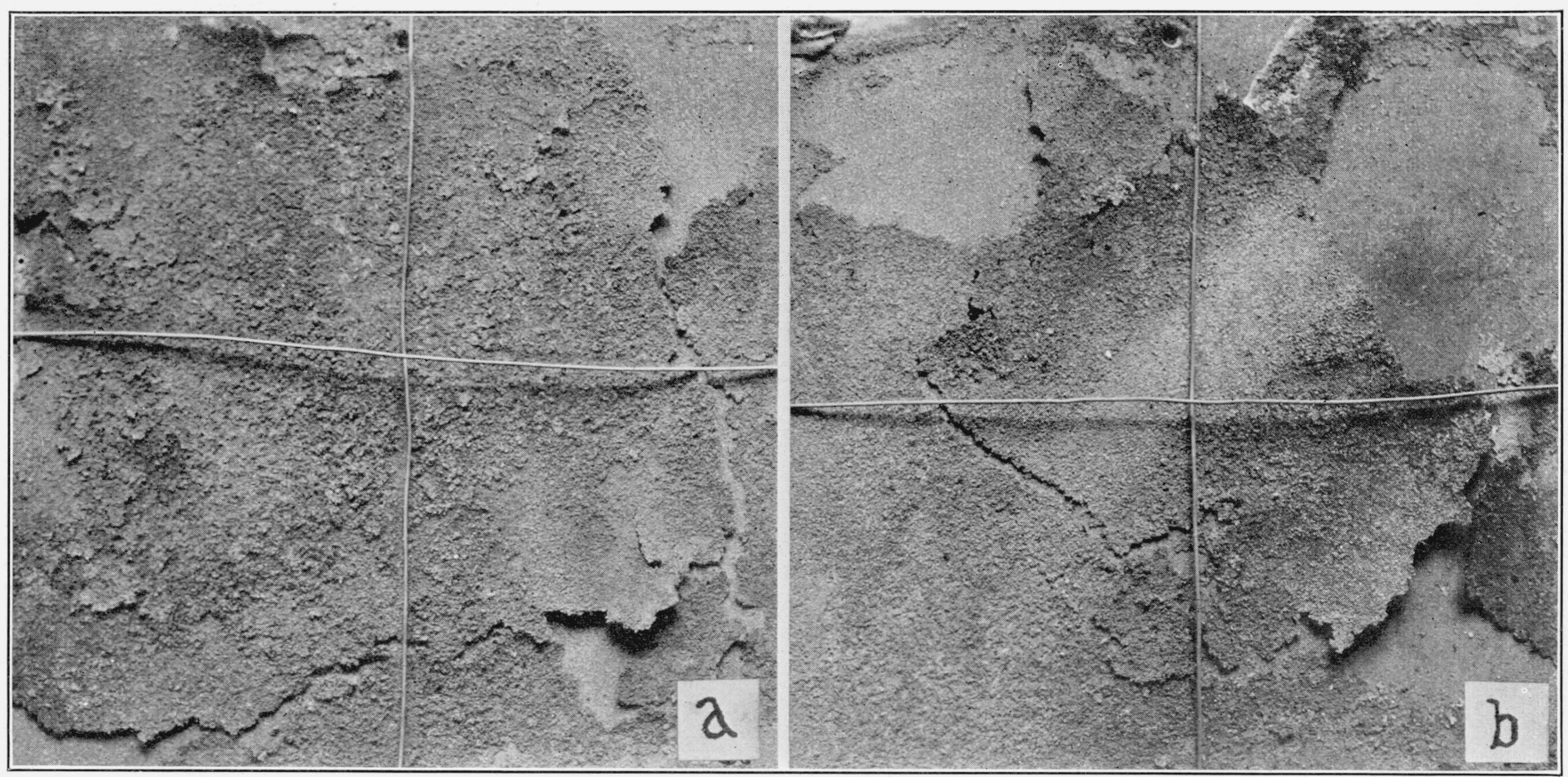

FIG. 22.-Comparison of the effect produced by the presence of copper in the base metal of hot-dipped galvanized sheets upon the coat of iron rust formed by prolonged exposure in the simulated atmospheric corrosion test. $\quad \times 1$

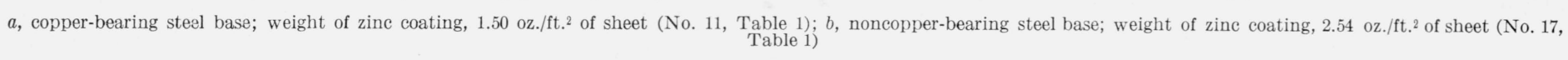




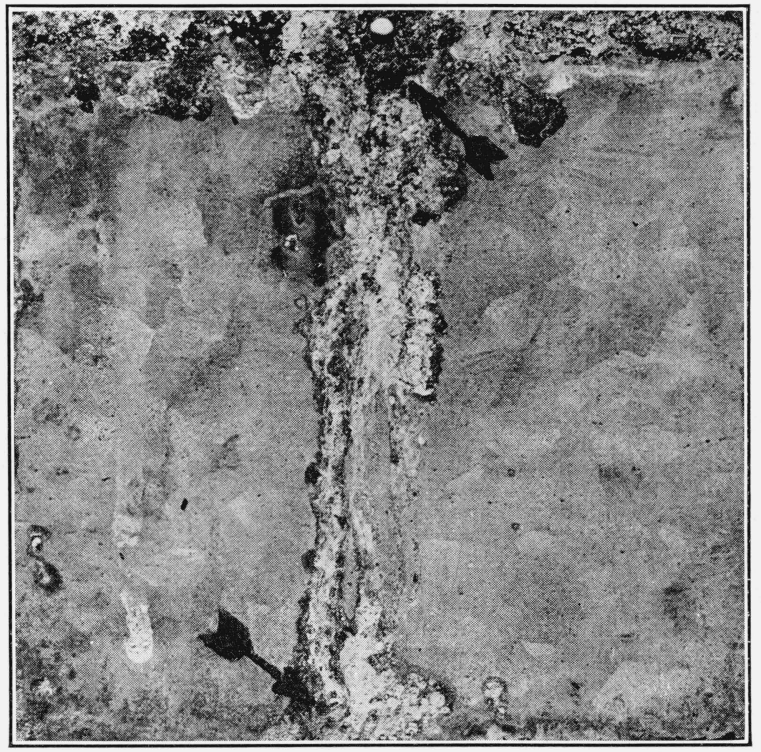

FIG. 23.-Change in appearance of a 0.9-ounce coating after 2,450 hours' exposure to sodium chloride spray. (Material No. 3, specimen KH1-1, Table 2.) $\times 3 / 4$

One type of corrosive attack was the formation of streaks extending from the upper edge downward and generally to the bottom edge, while the zinc coating lying between the streaks remained little affected. The breakdown of the coating occurred in these streaky areas, as evidenced by the formation of red-brown rust areas and spots (in this photograph, at the top and bottom ends of the central vertical streak, where indicated by arrows)

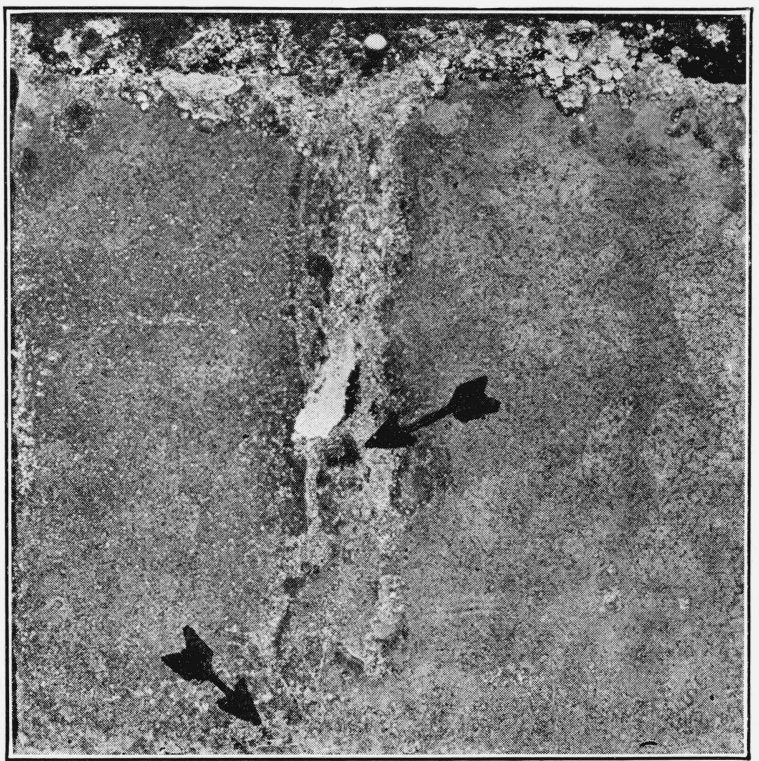

FIG. 24.-Same specimen as in Figure 23, but showing reverse side. $\quad \times 3 / 4$

A number of specimens were corroded in a general manner, as manifested by a strong dulling of the surface and the formation of numerous very small pits over a portion of or the entire surface and usually on only one face of the specimen. There were formed, in addition, vertical streaks where the breaking down of the coating usually occurred. In this photograph, iron rust is shown present at two points (indicated by arrows) in the vertical streak as dark patches 
should be kept in a vertical position, for it had been found ${ }^{17}$ that specimens of zinc-plated and hot-dipped galvanized sheets placed in the salt spray box in a vertical position corroded more rapidly than those in a horizontal or an inclined position. Type $(b)$ occurred in a large number of cases and apparently in a manner both capricious and independent of the kind of material, and type $(c)$ in a number of cases, in some of which the isolated area formed the lower terminus of an initially started vertical steak. These three types of surface attack are illustrated in Figures 23, 24, 25, 26, and 29. The breaking down of the zinc coating, as evidenced by the formation of red-brown iron rust, occurred at the top, bottom, or along the central vertical streak in the great majority of cases, although there were quite a few cases where the failure point was first reached along one or more vertical steaks lying between the central part and either right or left edge of the specimen or in other locations apart from the central vertical streak.

The progressive corrosion of the zinc coating at the places covered by these three types of surface attack was evidently due to "differential aeration" 18 which had been set up first in the film of liquid that had formed at the point in question and later in the overlying layer of corrosion products resulting from the preceding stages of the corroding process. Evans has stated the general truth that "corrosion is likely to persist most readily in places to which oxygen has least access, provided that these inaccessible places are not far removed from places to which oxygen can penetrate freely." Here the outlying portion of the liquid film had free access to the oxygen of the atmosphere while the oxygen content of the inner portion of the film adjacent to the metal surface became impoverished soon after the initiation of the electrochemical reaction in which the metal surface acted as the anode and the outer portion of the film as the cathode. The soluble zinc chloride produced at the anode reacted with the alkali produced at the cathodic portion to form zinc hydroxide, which precipitated out at a point intermediate between the anodic and cathodic portions. The presence of this wall of insoluble hydroxide served as a barrier to the inward diffusion of the oxygen, and, consequently, the subsequent corrosion was localized in the shielded metal surface. In other words, the corrosion product in the form of the insoluble zinc hydroxide served to shield the underlying metal surface from the oxygen supply, and the corrosion, which would otherwise have been spread over the whole area, tended to become concentrated at this shielded, or anodic, area. The fact that the spray tests were stopped at intervals, as for over Sundays and holidays, and the specimens thus had a chance to get dry, probably

17 See p. 28 of reference (b) cited in footnote 11.

18 U. R. Evans, Corrosion of Metals, E. Arnold \& Co., 2d ed.; 1926. 
accounts, in part at least, for the spreading out of the corroded area, since a compact layer of dried corrosion products often tends to protect the metal just below it and to concentrate attack upon the areas immediately surrounding it.

\section{(b) AMMONIUM CHLORIDE}

Two aspects must necessarily be given to the results obtained with this solution because of a peculiar situation, the existence of which was not realized until toward the end of the tests. The plotted data in Figure 7 are divided roughly into two distinct groups, one along curve 1 and the other along curve 2. The specimens of the first group were put into test and had reached the failure point before the simulated atmospheric corrosion tests were started in close proximity (about 3 feet) to the spray box. The cases coming under this group are indicated in Table 4 by the reference mark $\left(^{1}\right)$ before the average values; there was, however, one case (KA 1 specimens) where the specimens were put into test at the same time but did not reach the failure point till a long time after the start of the simulated atmospheric corrosion tests. The data for the specimens having different weights of coating up to about 2.0 ounces plotted along curve 1 were quite consistent with the course of the curve drawn. These specimens showed a "life" about half as long as the corresponding specimens in the sodium chloride spray tests.

The specimens in the second group and also the annealed specimens (plotted as crossed circles) were put into test at different times after the start of the simulated atmospheric corrosion tests and were, in the majority of cases, still in test when these other tests were completed. There was much irregularity in the data plotted along curve 2 and in the region lying between the two curves, even in the data for the noncopper-bearing steel base specimens having about 0.8 ounce coating. The specimens with the heavier coatings, 2.0 and 2.5 ounce, showed a very much longer "life" than should have been expected from the course of curve 1 .

It was suspected that this irregularity in results was due to conditions arising from the simultaneous operation of the simulated atmospheric corrosion test and the ammonium chloride spray test within a short distance of each other, even though in the latter the specimens were wholly inclosed. There was an occasional escape into the surrounding laboratory atmosphere of the gaseous mixture from the simulated atmospheric corrosion-test apparatus, especially while the tank covers were being exchanged before the washing stage. It should be added here that the sodium chloride spray box, which was kept in operation at the same time, was about 8 feet distant from the simulated atmospheric corrosion test apparatus and in the same direction as the ammonium chloride spray box. The sodium chloride spray test results did not show any such irregularities, even though 
specimens of the same materials were put into test in both spray boxes at the same or nearly the same times. An examination of a number of specimens taken from both spray boxes, especially those that had been kept in for 3,000 or more hours, showed that there was present, in the case of the ammonium chloride spray specimens, but not of the sodium chloride spray ones, a thin transparent film which was spread over the uncorroded portions of the specimen faces and could easily be scraped off with a safety razor blade as a fine white powder. On scraping the white deposit of corrosion products off from the corroded areas on a number of the heavier zinc-coated specimens which appeared to have reached the failure point $(4,000$ or more hours), as judged by the presence of small rust spots on the surface of these deposits, the underlying metal surface showed no evidences of the coating having broken down. These specimens are reported in Table 4 as having a "life" of over 5,000 hours. It was concluded that the misleading presence of the rust spots was due to particles of iron rust that had been carried down by the stream of condensed spray from the suspension hole, which was rusted, lodged in some favorable crevice in the deposit and then covered over with a thin coat of corrosion products. Several of the specimens, from which the deposits of corrosion products had been scraped off, were put back into test and, after several hundred hours' additional exposure, the zinc coating was found to have broken down at some point within the area previously covered by the depositof corrosion products.

Zinc has been reported ${ }^{19}$ to be attacked several times as fast, in the absence of carbon dioxide, when immersed in a 1 per cent solution of ammonium chloride as in sodium chloride solution of the same strength, and, in the presence of carbon dioxide, at about the same rate for both solutions. According to Snyders, ${ }^{20}$ zinc decomposes salt solutions, either concentrated or dilute, with the liberation of hydrogen gas and the formation of zinc oxide. This action is more pronounced if the oxide is soluble in the salt solution; this solubility is greatest in ammonium salts. The presence of oxide, without the addition of a carbonate, facilitates the solution of zinc in alkaline solutions. On the other hand, the presence of carbon dioxide retards, up to a certain point, the corrosive action by reason of the formation of a film of insoluble basic zinc carbonate which is spread over the surface.

It would seem that the explanation for the irregularity in the results obtained in the ammonium chloride spray test with those specimens, which were put into test after the simulated atmospheric corrosion tests

\footnotetext{
10 Wagner, A., Ueber den Einfluss verschiedener Lösungen auf Metalle. Dingler's Polytech. J., 221, p. 258: 1876. Also Comey's Dictionary of Chemical Solubilities: Inorganic. MacMillan Co., New York. ${ }^{20}$ Snyders, A. J. C., Die Chemische Wirkung von Wasser und von Salzlösungen auf Zink. Ber., 11 A, p. $936: 1878$.
} 
had been started, lies in the formation of a film of basic zinc carbonate that slowed down the otherwise relatively rapid attack of the ammonium chloride solution. In fact, as mentioned in a preceding paragraph, a thin transparent and strongly adherent film was found present on some of the ammonium chloride spray test specimens. Some of this film was scraped off, and the resulting white powder responded to a few qualitative tests for basic zinc carbonate and zinc oxide. Presumably the carbon dioxide gas, present in the atmosphere surrounding the spray box as a result of the escape of the gaseous mixture from the simulated atmospheric corrosion test apparatus, had reacted with the condensed ammonium chloride solution on the surfaces of the specimens to form this film of basic carbonate. Of course, any sulphur dioxide (or sulphurous acid) present would react with the zinc to form a zinc salt, but this gas was probably present in a considerably smaller proportion, and, therefore, the effect of the carbon dioxide would have preponderated. A similar action may have occurred in the sodium chloride spray box but to a much less degree, since the sodium chloride solution is more stable than the ammonium chloride solution.

The manner in which the zinc coating corroded and broke down was very similar to that described in Section V 2, $(a)$, p. 287. Figures 27 to 31 , inclusive, give typical illustrations of the corroding of the zinc coating in ammonium chloride spray.

Since it was clearly shown that the corroding attack produced by the ammonium chloride spray was entirely local in nature and not at all discriminating in bringing out the variations in the thickness of the coating on the specimen, no effort was made to repeat these tests for the purpose of straightening out the irregularity in the results. It is, however, obvious that due consideration must be given to the conditions surrounding the operation of the spray test in order that the possibility of interfering factors may be avoided.

\section{SUMMARY AND CONCLUSIONS}

The purpose of this investigation was the comparison of the merits of two certain types of accelerated laboratory testing methods for evaluating the life of the zinc coating on hot-dip galvanized materials that have been employed by other investigators in testing zinccoated materials. These two types of testing methods were the simulated atmospheric corrosion and the spray. The test specimens were exposed, in the first type, to a concentrated form of a moist acidic atmosphere which is found prevalent in industrial centers and some large cities and, in the second, to normal solutions of sodium chloride and ammonium chloride, used separately, in the form of a fog or mist. The "life" of the zinc coating was determined by noting the number of cycles (each 24-hour cycle consisting of three 


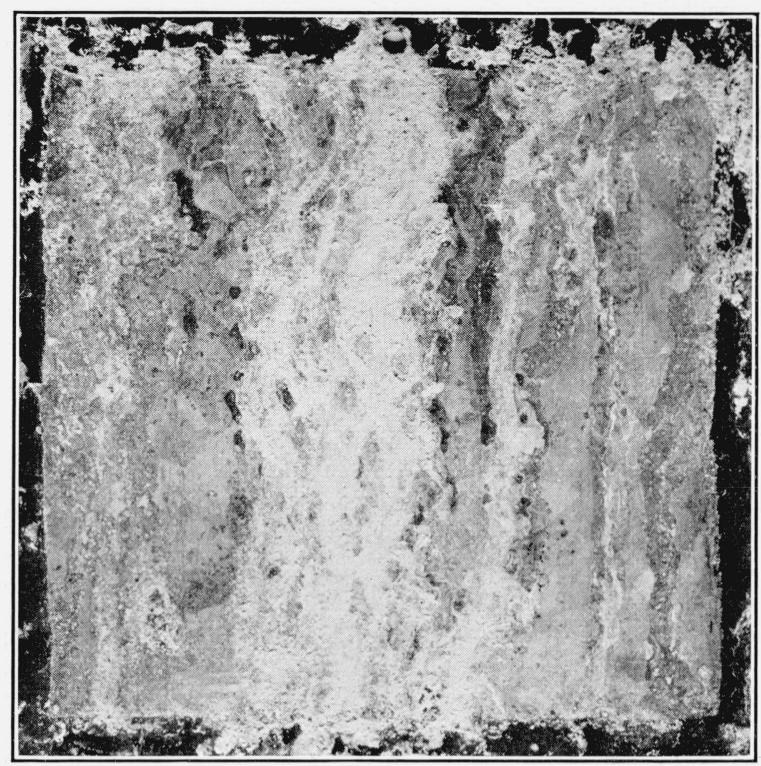

FIG. 25.-Change in appearance of a 2.0-ounce coating after 2,180 hours' exposure to sodium chloride spray. (Material No. 14, specimen SB2-11, Table 2.) $\times 3 / 4$

A number of specimens were heavily corroded in a manner similar to that shown here. The central vertical streak was heavily encrusted with corrosion products, and several iron rust spots were present in this streak, thus indicating that the coating had broken down at these points (these rust spots are not brought out in this photograph in a well-contrasted manner)

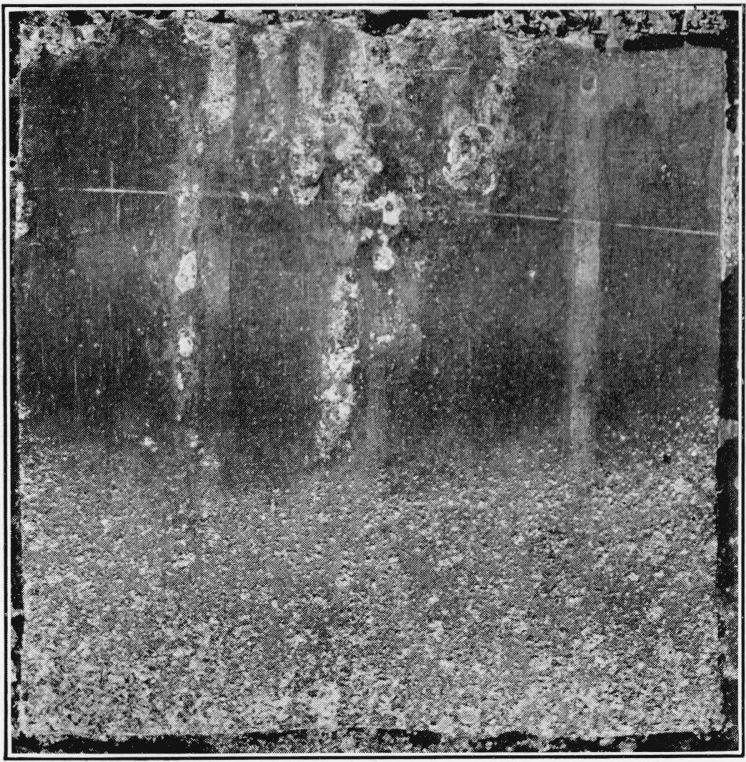

FIG. 26.-Change in appearance of a specimen of lead-coated material after 1,560 hours' exposure to sodium chloride spray. (Material No. 35, specimen SSSL-111, Table 2.) $\times 3 / 4$

Both the streaky and generally corroded types of corrosive attack occurred on this face of the leadcoated specimen. Numerous small iron rust spots were scattered above the lower edge and in portions of the different vertical streaks. The lead coat was roughened in the generally corroded area and in part along the streaks, while it remained smooth in the portions lying between the streaks 
B. S. Journal of Research, RP10

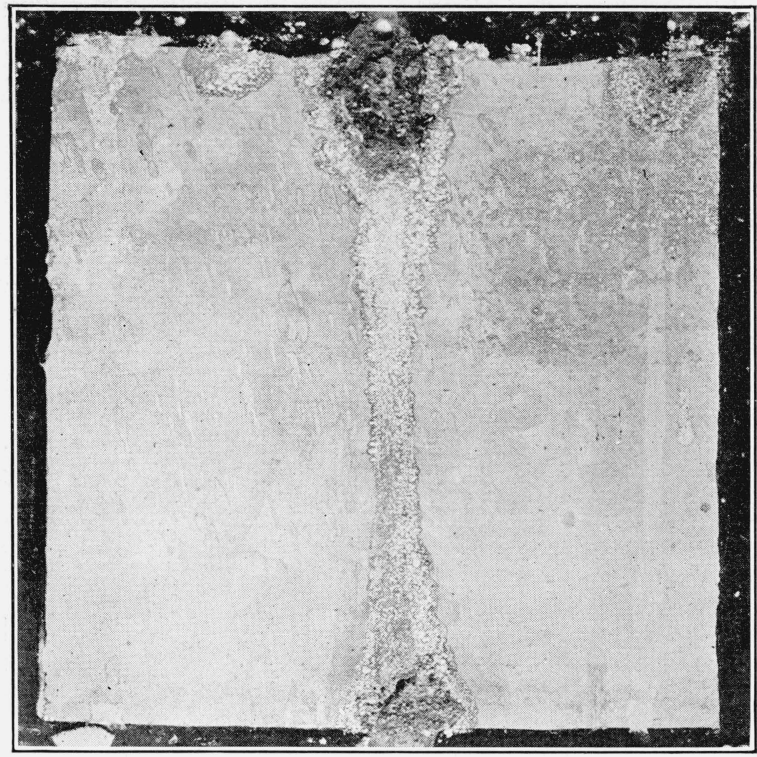

FIG. 27.-Change in appearance of a 0.9-ounce coating after 2,560 hours' exposure to ammonium chloride spray. (Material No. 2, specimen SH2-1, Table 2.) $\times 3 / 4$

A heavy deposit of iron rust is present at the top and bottom ends of the central streak and at the top of the streak near the right edge

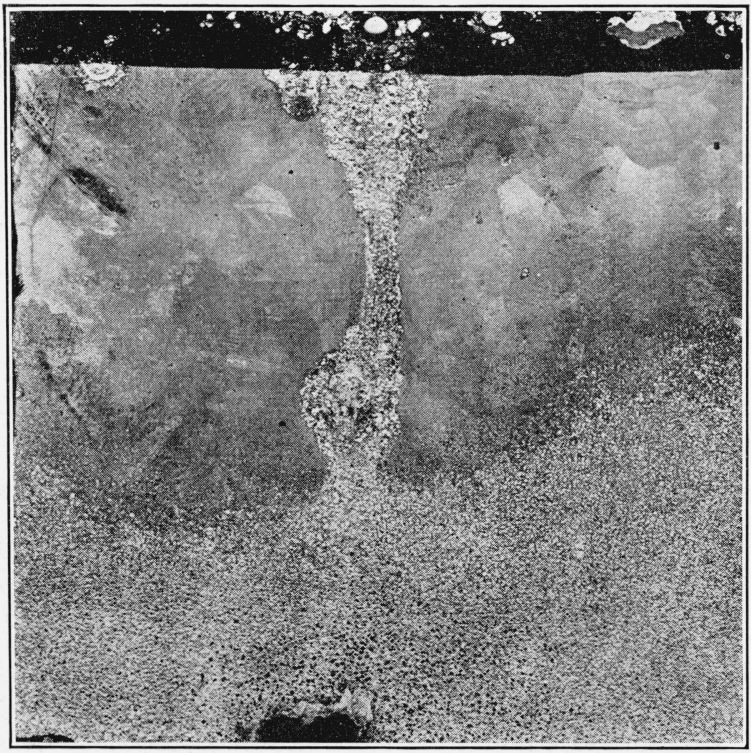

FIG. 28.-Change in appearance of an 0.8-ounce coating after 1,070 hours' exposure to ammonium chloride spray. (Material No. 23, specimen $K K 1-11$, Table 2.) $\times 3 / 4$

The vertical streak at the center had formed before the general corroding of the lower half had developed. Clusters of small iron rust spots had formed in the top and middle of the vertical streak, and a considerable part of the corroded area in the lower half was covered with a yellowcolored rust. At the bottom of the vertical streak the coating had been entirely removed, thus leaving bare a good-sized area of the base metal, part of which was covered with an adherent coat of iron rust (shown very dark in the photograph) 


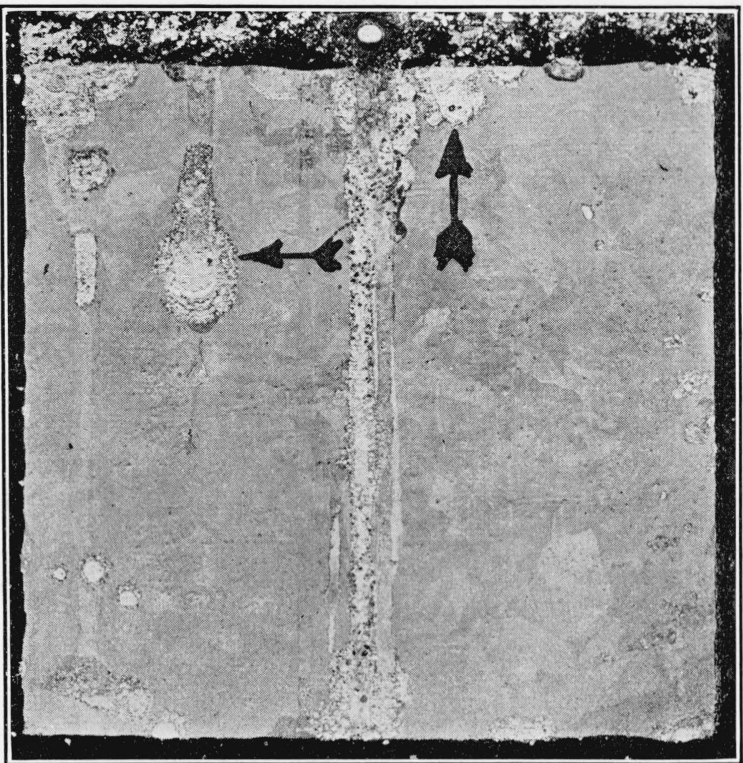

FIG. 29.-Change in appearance of a 1.5-ounce coating after 1,530 hours' exposure to ammonium chloride spray. (Material No. 12, specimen KC2-11, Table 2.) $\times 3 / 4$

The coating had broken down on localized corroded areas, as was evidenced by the presence of single small rust spots at the places indicated in the photograph by the arrows. The base metal was laid bare in one fair sized and several small areas at the top of the central vertical streak by the complete removal of the coating; these areas of exposed base metal are fairly well brought out in the photograph

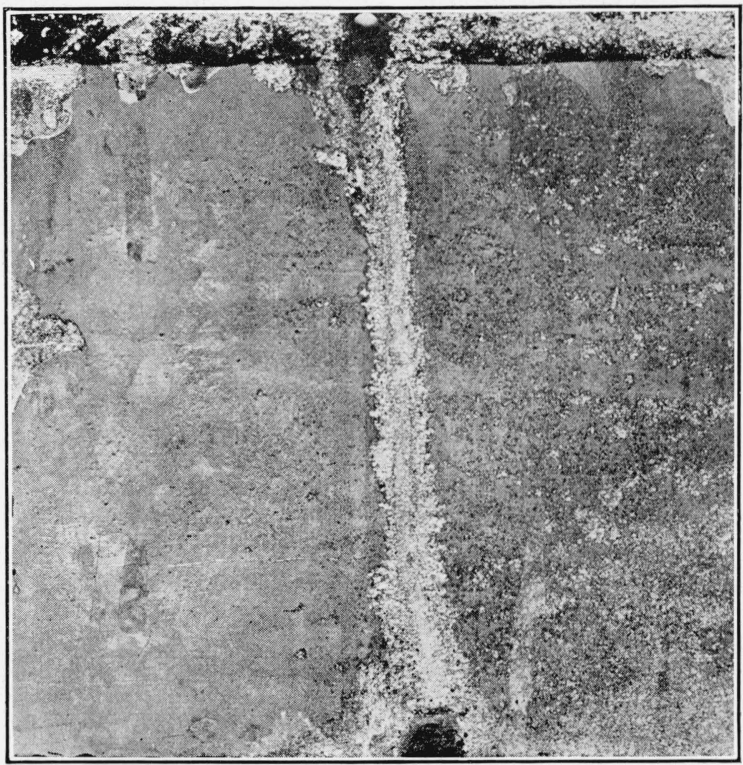

FIG. 30.-Change in appearance of 1.2-ounce coating after 1,070 hours' exposure to ammonium chloride spray. (Material No. $\%$, specimen $K E 1-1$, Table 2.) $\times 3 / 4$

Fairly good-sized areas of the base metal have been laid bare at the top and bottom of the central vertical streak by the complete removal of the coating. Iron rust was present at the borders of these base metal areas. The right half of the specimen was corroded in a general manner, although no evidence of the coating as having broken down anywhere in this portion was present 
B. S. Journal of Research, RP10

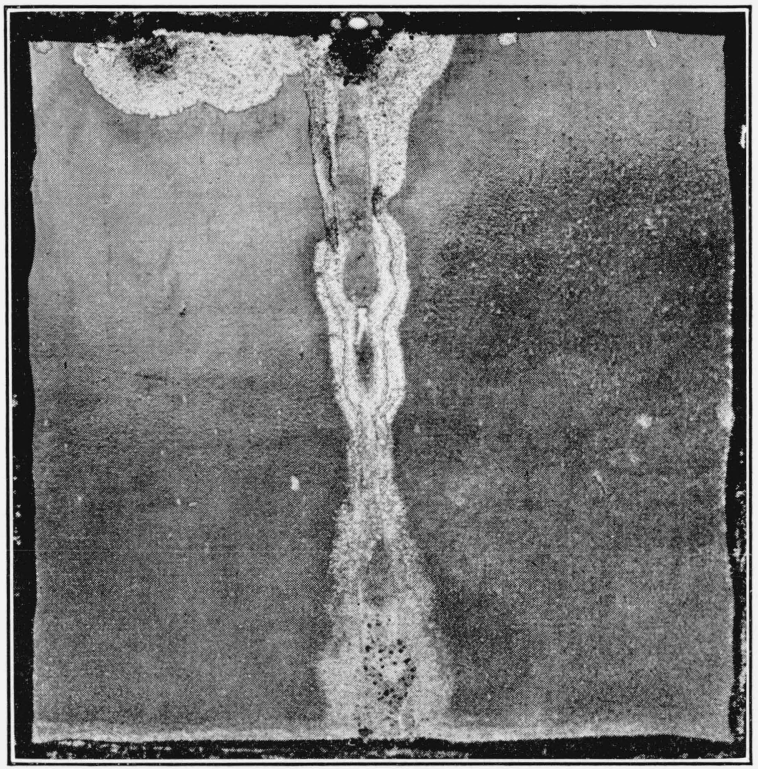

FIG. 31.-Change in appearance of specimen of "commercially heat-treated" material after 1,125 hours' exposure to ammonium chloride spray. (Material No. 36, specimen SSSG-11, Table 2.) $\times 3 / 4$

This photograph shows that about three-quarters of the light gray matte-like galvannealed coating had changed color to a blue-black, and that iron rust had formed at the top and bottom (as a cluster of small spots) of the vertical streak and at the upper edge near the left corner 
stages: (a) 5 hours exposure to a warm moist gaseous mixture of, by volume, 5 parts $\mathrm{CO}_{2}, 1$ part $\mathrm{SO}_{2}$, and 94 parts air; (b) 1 hour to water spraying, emulating the action of rain; and (c) 18 hours air drying) for the first type and the number of hours for the second which were required to produce a breaking down of the coating as evidenced by the first definite appearances of iron rust due to the corroding of the underlying iron or steel base. No attempt was made to interpret the results of these tests in terms of service life in various types of atmospheres prevailing in different climates. Any satisfactory attempt at such an evaluation will have to await the results of long-time field tests on galvanized products carried out at various locations where different typical atmospherical conditions prevail. Fortunately, there is now in progress in this country, under the auspices of the American Society for Testing Materials, such a series of field tests on various classes of galvanized products.

In the simulated atmospheric corrosion tests a consistent relation was obtained between the "life" of the coating, represented by cycles, and the weight of the zinc coating. The time required to produce a breakdown of the coating was within reasonable limits for a laboratory testing method, about three to four weeks being required for sheet materials with 2.5-ounce coating exposed to the concentration of gases and for the comparatively short time per cycle employed in these tests. The rate of the loss in weight of the coating was found, experimentally, to vary from cycle to cycle for individual specimens, but that the average loss in weight per cycle and also the ratio of the initial weight of coating to the total loss in weight approached constant values, which were independent of the initial weight of the coating, for the series of tests.

In the spray tests, the results for the sodium chloride solution showed a quite consistent relationship between the "life" of the coating, expressed in hours, and the weight of coating. However, the time required for the breaking down of the coating was considerable, about 3,000 hours, or 125 days, being needed for specimens with a 2.5-ounce coating. In the tests with ammonium chloride solution the results obtained for about half of the specimens which were tested before the simulated atmospheric corrosion tests had been started in close proximity to the spray boxes showed about twice as short a "life" as for the corresponding specimens in the sodium chloride spray tests. The results for the remainder of the specimens, which were put into test during the progress of the simulated atmospheric corrosion tests, were complicated by the formation of a film of corrosion products which materially slowed down the rate of corrosion. The formation of this film is ascribed to the occasional presence in the laboratory atmosphere of gases that had come from the simulated atmospheric corrosion test apparatus. 
The manner in which the zinc coating was attacked was altogether different in the two types of testing methods. In the simulated atmospheric corrosion test method the coating was removed in a progressive manner over the entire surface from the zinc metal layer down through the outer and inner iron-zine alloy layers to the base metal, generally starting at the points where the coating was thinnest. This progressive removal of the coating was similar to that reported for galvanized materials exposed to the atmosphere under service conditions. With both solutions in the spray test method the specimens were corroded in an entirely local and capricious manner, depending on the distribution of the condensed spray over the surface of the specimen and usually along the vertical central portions where the specimen was suspended. Corrosion progressed at these points through differential aeration. The portions of the surface lying between the corroded areas oftentimes remained uncorroded: This absence of a selective corroding of the coating, whereby the thinnest portions of the coating are revealed, constitutes a serious drawback for the spray test method in comparing the merits of the two types of testing.

The presence of 0.2 per cent copper in the steel base metal produced no observable effect on the "life" of the zinc coating as compared with that of the coating on noncopper-bearing steel sheets.

The results for the sheet materials with imperfect coatings, such as gray galvanized, stringy, and blistered, were consistent in showing a somewhat lower "life" than the regular sheet materials of good quality in all the tests.

Results obtained with a number of hot-dip galvanized sheet specimens, which had been annealed at $500^{\circ} \mathrm{C}$. $\left(932^{\circ} \mathrm{F}\right.$.) for one-half hour for the purpose of converting as much of the zinc coating into an evenly distributed iron-zinc alloy as practicable, showed that this converted coating was somewhat more resistant than the normal nonannealed coating in the simulated atmospheric corrosion test but was decidedly less resistant in the sodium chloride spray test. The slower action in the former case seems possibly due to the absence of overlying portions of a zinc metal layer, whereby the general corrosive attack would have been accelerated by the reaction between the anodic zinc metal layer and the cathodic iron-zinc alloy layer. It appears probable that the more rapid action in the latter case is caused by a greater tendency for electrolytic action on the part of the alloy than of zine metal in the presence of sodium chloride solution.

In the light of the above-reported results, the simulated atmospheric corrosion test method appears to give much promise as an accelerated laboratory corrosion testing method for zinc coatings that would be of value to the industry, particularly for development work where a comparative measure of the probable service behavior 
under the severest atmospheric conditions of products coated by new or improved processes is to be desired. It is hardly to be recommended for routine testing wherein information as to the weight and uniformity in thickness of the coating is the sole objective, for the stripping tests now employed for this purpose are sufficiently adequate and less time consuming. There seems to be no reason why an automatically operated apparatus for the simulated atmospheric corrosion test method could not be developed, whereby the testing work would be facilitated to a marked degree. The spray test method, at least as used with normal solutions of sodium chloride and ammonium chloride as the corrodent, has failed to show any merits which would recommend it as an accelerated test method for evaluating the service life of hot-dip zinc coatings.

The authors wish to express their sincere appreciation to H. S. Rawdon and H. W. Gillett, of the division of metallurgy, Bureau of Standards, for helpful suggestions made in the course of this work.

Washington, May 4, 1928. 



\title{
THE JULY, 1928, NUMBER OF THE JOURNAL
}

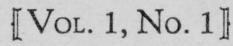 \\ contains the following Research Papers:
}

RP1. Accelerated tests of organic protective coatings. Percy $\mathbf{H}$. Walker and E. F. Hickson.

RP2. Measurement of the tread movement of pneumatic tires and a discussion of the probable relation to tread wear. W. L. Holt and C. M. Cook.

RP3. Absolute methods in reflectometry. H. J. McNicholas.

RP4. Interferometer measurements of wave lengths in the vacuum arc spectra of titanium and other elements. C. C. Kiess.

RP5. Analysis of bauxite and of refractories of high alumina content. G. E. F.Lundell and J. I. Hoffman.

These will be available as separates for purchase from the Superintendent of Documents, Government Printing Office, Washington, D. C.

Bureau researches concern specifically fundamental science and the laws of matter and energy; physical constants and other basic data in the form of tables, equations, nomograms, or other graphs; the properties of materials, structures, and devices and their effective design and performance; the mitigation of injurious effects of such agencies as fire, corrosion, breakage; the promotion of efficiency by scientific measured control of processes through experimental and theoretical research in the fields of physics, chemistry, engineering, and the special technologies, such as:

Electricity

Magnetism

Radio communication

Photometry

Radioactivity

Length

Mass

Capacity

Density

Time

Radiometry
Spectroscopy

Colorimetry

Polarimetry

Atomic physics

Electrochemistry

Gas chemistry

Heat and power

Thermometry

Pyrometry

Fire resistance

Refrigeration
Mechanics

Sound

Aeronautics and derodynamics

Metallurgy

Textiles, paper, leather, and rubber

Structural materials

Cement

Ceramics

Optical glass, etc.

Several hundred researches are in progress at the Bureau of Standards and the outlet for the results is the Bureau of Standards Journal of Research. 